\title{
RESEARCH
}

Open Access

\section{Modulating gut microbiota in a mouse model of Graves' orbitopathy and its impact on induced disease}

Sajad Moshkelgosha ${ }^{1,2 \dagger}$, Hedda Luise Verhasselt ${ }^{3,4 \dagger}$, Giulia Masetti, ${ }^{5,6,7 \dagger}$, Danila Covelli, ${ }^{4,8}$, Filippo Biscarini ${ }^{6,9}$, Mareike Horstmann ${ }^{1}$, Anke Daser ${ }^{10}$, Astrid M. Westendorf ${ }^{3}$, Christoph Jesenek', Svenja Philipp', Salvador Diaz-Cano ${ }^{11}$, J. Paul Banga', Daryn Michael ${ }^{4}$, Sue Plummer ${ }^{4}$, Julian R. Marchesi ${ }^{12,13}$, Anja Eckstein ${ }^{10^{* *}}$, Marian Ludgate ${ }^{5^{*}+}$ (D) Utta Berchner-Pfannschmidt ${ }^{1^{* \dagger}}$ and and the INDIGO consortium

\begin{abstract}
Background: Graves' disease (GD) is an autoimmune condition in which autoantibodies to the thyrotropin receptor (TSHR) cause hyperthyroidism. About 50\% of GD patients also have Graves' orbitopathy (GO), an intractable disease in which expansion of the orbital contents causes diplopia, proptosis and even blindness. Murine models of GD/GO, developed in different centres, demonstrated significant variation in gut microbiota composition which correlated with TSHR-induced disease heterogeneity. To investigate whether correlation indicates causation, we modified the gut microbiota to determine whether it has a role in thyroid autoimmunity. Female BALB/c mice were treated with either vancomycin, probiotic bacteria, human fecal material transfer (hFMT) from patients with severe GO or ddH2O from birth to immunization with TSHR-A subunit or beta-galactosidase ( $\beta$ gal; age $\sim 6$ weeks). Incidence and severity of GD (TSHR autoantibodies, thyroid histology, thyroxine level) and GO (orbital fat and muscle histology), lymphocyte phenotype, cytokine profile and gut microbiota were analysed at sacrifice ( 22 weeks).

(Continued on next page)
\end{abstract}

\footnotetext{
*Correspondence: Anja.Eckstein@uk-essen.de; Ludgate@cardiff.ac.uk; Utta.Berchner-Pfannschmidt@uk-essen.de

Filippo Biscarini is currently seconded to the European Research Council Executive Agency (ERCEA), Brussels, Belgium. The views expressed here are purely those of the writer and may not in any circumstances be regarded as stating an official position of the European Commission.

${ }^{+}$Sajad Moshkelgosha, Hedda Luise Verhasselt and Giulia Masetti contributed equally to this work.

${ }^{\dagger}$ Anja Eckstein, Marian Ludgate, Utta Berchner-Pfannschmidt share joint senior authorship

${ }^{10}$ Department of Ophthalmology, University Hospital Essen, University of Duisburg-Essen, 45147 Essen, Germany

${ }^{5}$ Division of Infection \& Immunity, School of Medicine, Cardiff University, UHW main building, Heath Park, Cardiff CF14 4XW, UK

${ }^{1}$ Molecular Ophthalmology, Department of Ophthalmology, University Hospital Essen, University of Duisburg-Essen, 45147 Essen, Germany Full list of author information is available at the end of the article
}

(c) The Author(s). 2021 Open Access This article is licensed under a Creative Commons Attribution 4.0 International License, which permits use, sharing, adaptation, distribution and reproduction in any medium or format, as long as you give appropriate credit to the original author(s) and the source, provide a link to the Creative Commons licence, and indicate if changes were made. The images or other third party material in this article are included in the article's Creative Commons licence, unless indicated otherwise in a credit line to the material. If material is not included in the article's Creative Commons licence and your intended use is not permitted by statutory regulation or exceeds the permitted use, you will need to obtain permission directly from the copyright holder. To view a copy of this licence, visit http://creativecommons.org/licenses/by/4.0/ The Creative Commons Public Domain Dedication waiver (http://creativecommons.org/publicdomain/zero/1.0/) applies to the data made available in this article, unless otherwise stated in a credit line to the data. 
(Continued from previous page)

Results: In ddH2O-TSHR mice, 84\% had pathological autoantibodies, 67\% elevated thyroxine, 77\% hyperplastic thyroids and $70 \%$ orbital pathology. Firmicutes were increased, and Bacteroidetes reduced relative to ddH2O- $\beta$ gal; CCL5 was increased. The random forest algorithm at the genus level predicted vancomycin treatment with $100 \%$ accuracy but 74\% and 70\% for hFMT and probiotic, respectively. Vancomycin significantly reduced gut microbiota richness and diversity compared with all other groups; the incidence and severity of both GD and GO also decreased; reduced orbital pathology correlated positively with Akkermansia spp. whilst IL-4 levels increased. Mice receiving hFMT initially inherited their GO donors' microbiota, and the severity of induced GD increased, as did the orbital brown adipose tissue volume in TSHR mice. Furthermore, genus Bacteroides, which is reduced in GD patients, was significantly increased by vancomycin but reduced in hFMT-treated mice. Probiotic treatment significantly increased CD25 $5^{+}$Treg cells in orbital draining lymph nodes but exacerbated induced autoimmune hyperthyroidism and $\mathrm{GO}$.

Conclusions: These results strongly support a role for the gut microbiota in TSHR-induced disease. Whilst changes to the gut microbiota have a profound effect on quantifiable GD endocrine and immune factors, the impact on GO cellular changes is more nuanced. The findings have translational potential for novel, improved treatments.

Keywords: Graves' disease, Graves' orbitopathy, Murine model, Gut microbiota, Microbiome modulation, Vancomycin, Probiotics, Human fecal microbiota transplant

\section{Background}

There is an interdependent relationship between the host immune system and the gut microbiota. Differentiation of naive $\mathrm{CD}^{+} \mathrm{T}$ cells in the gut-associated lymphoid tissue is modulated by microbial metabolites [1]. Consequently, autoimmune disease, including type-1 diabetes (T1D) and multiple sclerosis (MS), is influenced by the gut microbiota composition [2-7]. Perturbation of the gut microbiota may improve or exacerbate autoimmunity, for example, administration of antibiotic to female systemic lupus erythematosus-prone mice attenuates disease [8], but human fecal material transfer (hFMT) from MS patients increased the frequency of murine autoimmune encephalomyelitis (EAE) [9]. In contrast, administration of probiotics to EAE mice resulted in a milder disease phenotype [10] and reduced inflammation in a model of autoimmune thyroid disease (ATD) [11].

Little is known regarding the role of the microbiome in Graves' disease (GD), which is characterized by thyroid-stimulating antibodies (TSAbs) binding to the thyrotropin (TSH) receptor (TSHR) resulting in thyroid hyperplasia and hyperthyroidism [12-14]. The TSHR is expressed in orbital fibroblasts and up to $50 \%$ of GD patients also have Graves' orbitopathy (GO), in which orbital tissue remodeling causes eye redness, swelling, diplopia, proptosis and vision impairment [15-17]. Genetic background and environmental factors, e.g. stress, smoking and pregnancy, combine to increase predisposition to GD and GO [18-22]. Bacterial infections have also been implicated [23], as have immune responses to food and other antigens [24].

We recently described a relationship between the gut microbiota and thyroid autoimmunity [25] in a robust
GO mouse model in which female BALB/c (H-2d) mice were immunized with the TSHR-A subunit (TSHR extracellular region) via plasmid electroporation [26, 27]. Differences in the induced disease were noted in the same mouse strain $(B A L B / c)$ but in two different laboratories, e.g. hyperthyroidism only in one centre accompanied by significant differences in alpha-diversity, betadiversity and taxonomic profiles between the two centres. We also observed a shift in beta-diversity of bacterial communities in TSHR-immunized mice compared to controls and a positive correlation between Firmicutes and orbital adipogenesis $[25,28]$. When comparing mice of differing strains (BALB/C and C57BL/6J), but in the same housing, we observed variations in orbital pathology, TSAbs, thyroxine levels and inflammation, accompanied by differences in microbiome composition. Bacterial genera were also correlated with disease features, e.g. Clostridium-IV and Anaerotruncus spp. positively correlated with TSAb levels in BALB/c mice whereas Limibacter spp. correlated negatively with TSAbs in C57BL/6J mice $[25,28]$.

However, correlation does not imply causation, and to test the microbiota contribution to the GO model from early life, we modulated its composition and assessed induced disease phenotype.

\section{Materials and methods Mouse model and study outline}

Female BALB/c mice used in this study were bred at the Central Animal Laboratory, University Hospital Essen, University of Duisburg-Essen, Essen, in order to administer the treatments from an early stage of life. Breeding pairs were purchased from Harlan, now Envigo, Rossdorf, Germany. In total, 95 mice were included in the study. Three of the 95 mice died for unknown reasons. The 
mouse cohort was divided into four groups receiving either (i) the antibiotic vancomycin, (ii) the probiotic consortium Lab4, (iii) freeze-dried human fecal material from severely diseased GO patients and (iv) deionized water $\left(\mathrm{ddH}_{2} \mathrm{O}\right)$ as control. The antibiotic vancomycin was provided in autoclaved drinking water at a dose of $0.2 \mathrm{~g} / \mathrm{l}$ to both dams first and pups later from their first day of life for the entire course of the experiment. The probiotic Lab4 (Cultech Ltd., Port Talbot, Wales, UK) is a consortium comprising two strains of Lactobacillus acidophilus CUL60 (NCIMB 30157) and CUL21 (NCIMB 30156), Bifidobacterium lactis CUL34 (NCIMB 30172) and Bifidobacterium bifidum CUL20 (NCIMB 30153). It was provided as powder in a capsule, and loose powder was administered at a total of $1 \times 10^{10} \mathrm{CFU}$ in $50 \mu \mathrm{l}$ autoclaved water per gavage. The hFMT powder was dissolved in autoclaved water and provided at a final concentration of $1 \times$ $10^{10} \mathrm{CFU}$ in $50 \mu \mathrm{l}$ autoclaved water per gavage. Administration of the probiotic Lab4, the hFMT powder and $\mathrm{ddH}_{2} \mathrm{O}$ as control was performed through gavage on pups a total of four times from the first day after birth, at weaning, and before and in the mid of the immunization procedure, as described in Fig. 1a.

At an age of 6-7 weeks and after having received three gavages or vancomycin continuously, mice from each group were assigned to two subgroups for receiving immunization with either the human thyrotropin receptor (hTSHR)-A subunit (hTSHR) eukaryotic expression plasmid pTriEx1.1Neo-hTSHR (hTSHR289) or the control plasmid pTriEx1.1Neo- $\beta$-gal, as a plasmid-control group ( $\beta$ gal) via intramuscular injection with $50 \mu \mathrm{l}$ (1 $\mathrm{mg} / \mathrm{ml}$ ) into each $\mathrm{M}$. biceps femoris and electroporation four times at three week intervals $[26,29,30]$. All plasmids were purified from E. coli extracts and stored aliquoted at $-80^{\circ} \mathrm{C}$. As an electroporation system, a BTX Gemini X2 with $7-\mathrm{mm}$ calliper electrodes at $120 \mathrm{~V} / \mathrm{cm}$ was used with current application in two series of six $20-\mathrm{msec}^{2}$ wave pulses at $1 \mathrm{~Hz}$. Anaesthesia of each mouse was conducted with an isoflurane vaporizer throughout the immunization procedure. Mice were kept in individually ventilated cages under specific pathogen-free (SPF) conditions throughout the study. Animals were fed water and commercial diet ad libitum. Animals were sacrificed 6 weeks after the last immunization or at an age of 22 weeks, respectively. Mouse weights were noted at the endpoint of the study (balance 440-45N (Kern und Sohn GmbH, Balingen, Germany).

Recruitment of patients with severe Graves' orbitopathy for human fecal microbiota transplant (hFMT) production Six Graves' orbitopathy patients with sight-threatening disease were recruited at the Ophthalmic Clinic of the University Hospital of Duisburg-Essen (Germany). Eye disease activity and severity were assessed based on the EUGOGO guidelines [31]. Five of the six patients stopped steroid intake at least 2 months prior to sample collection, whereas one patient took steroids in the month of sampling. None of the six patients received immunosuppressive drugs before sampling, and receipt of antibiotics in the previous 3 months excluded potential donors. All six patients were treated with steroid bolus and selenium before orbital decompression surgery (performed between 2014 and 2015). One patient (GO 4) had the decompression of both eyes, and two patients (GO 4 and GO 5) continued steroid treatment after surgery. Assessment of thyroid blood parameters (TSH and total serum T4) and thyroid-stimulating antibodies (TRAB) was performed according to bioassays used in the central laboratory at University Hospital Essen, Germany. A complete description of the patient characteristics used for hFMT production is described in Table S1. Donors were instructed in person before the procedure regarding stool collection and delivery. Subsequent fecal samples were collected at the time of enrolment, stored at $-80^{\circ} \mathrm{C}$ and shipped frozen to Cultech Ltd. (Port Talbot, UK) for the production of the fecal microbiota transplant (hFMT). Each single fecal sample underwent traditional microbial cultures and DNA extraction for $16 \mathrm{~S}$ rRNA gene sequencing.

\section{Production of freeze-dried fecal bacteria for human fecal microbiota transplant (hFMT)}

To assess numbers of living bacteria in feces, 1 gram of feces per patient was diluted in $9 \mathrm{ml}$ pre-reduced maximum recovery diluent (CM0733, Oxoid, Basingstoke, UK) with $20 \% \mathrm{v} / \mathrm{v}$ glycerol. The solution was mixed by vortexing for $5 \mathrm{~s}$. Then, 10 -fold serial dilutions were prepared, and $100 \mu \mathrm{l}$ of each dilution was plated onto different culture media under aerobic or anaerobic conditions (Anaerobic Workstation, AW400SG, Elektrotek, Keighley, West Yorkshire, UK). In order to isolate different bacteria, the following media, culture conditions and dilutions were used as described in [25], see additional methods. For hFMT production, blended fecal samples were run through a sequential culture method. Therefore, $0.1 \mathrm{~g}$ of pooled and blended feces was added to 50 $\mathrm{mL}$ pre-reduced maximum recovery diluent (MRD) broth and incubated overnight at $37^{\circ} \mathrm{C}$ under aerobic and anaerobic conditions. The mixture was further inoculated into $500 \mathrm{~mL}$ pre-reduced MRD, followed by an overnight incubation at $37^{\circ} \mathrm{C}$ under aerobic and anaerobic conditions. As a control, pooled fecal samples from each inoculum were plated on the non-selective agars horse blood agar and anaerobic blood agar (both purchased from Thermo Fisher Scientific Oxoid Ltd, Basingstoke, UK) and incubated overnight at $37^{\circ} \mathrm{C}$ under aerobic or anaerobic conditions in order to count viable 


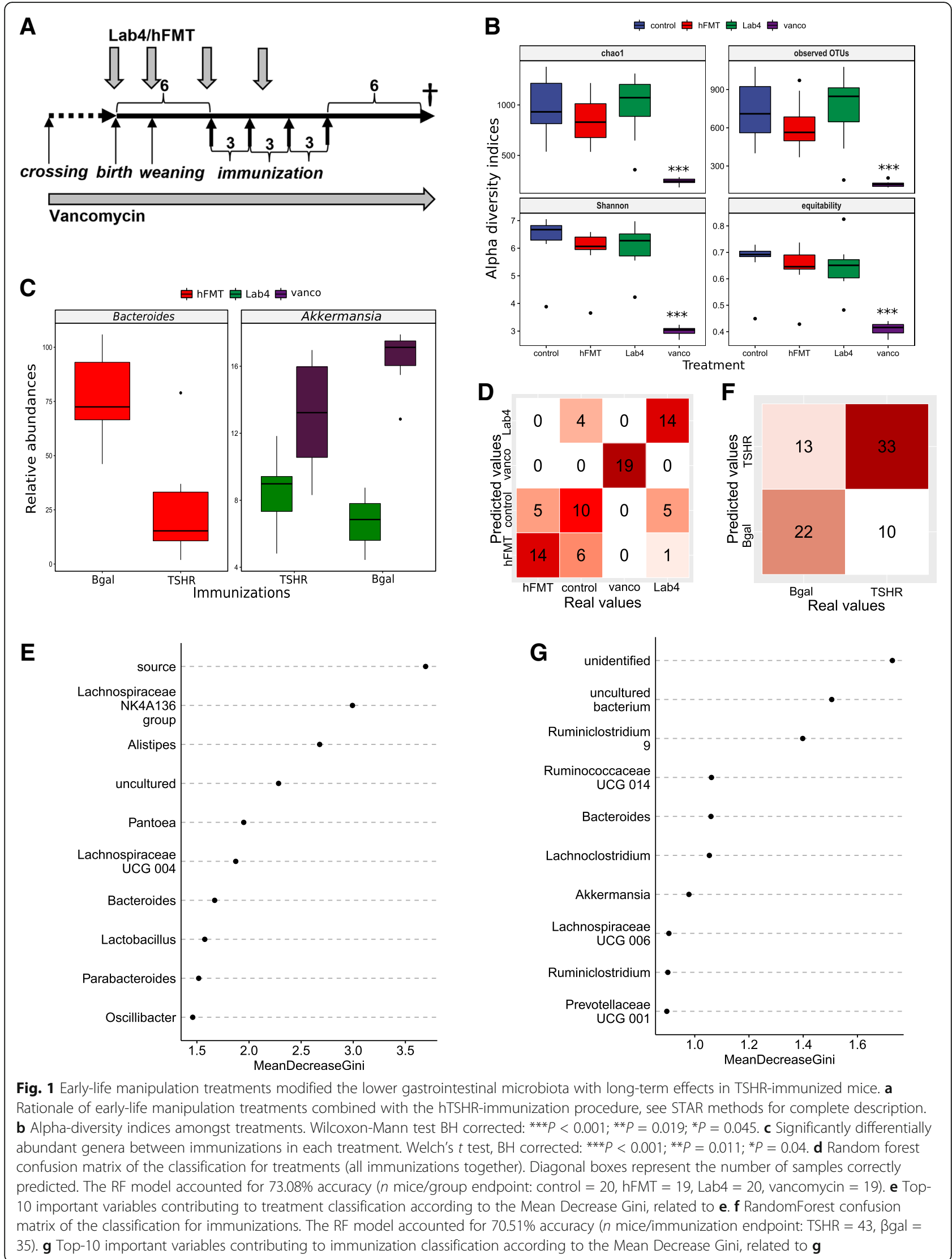


cells. After a centrifugation step at $3000 \times g$ for $30 \mathrm{~min}$, the resulting supernatant was discarded and the pellet was weighed and poured into sterile petri dishes, where they were supplemented with $10 \% \mathrm{w} / \mathrm{v}$ skimmed milk powder as a cryoprotectant agent, and placed at $-80^{\circ} \mathrm{C}$ until completely frozen. The freeze-drying process was performed in a freeze-dryer machine (Super Modulyo freeze dryer, Edwards, Clevedon, North Somerset, UK). The frozen sample was moved into the freeze-drier with a shelf temperature of $-30^{\circ} \mathrm{C}$; afterwards, the vacuum was started, the temperature was slowly decreased to $15^{\circ} \mathrm{C}$ and the samples were kept under these conditions overnight. Finally, the temperature was raised to 0 for 2 $\mathrm{h}$ and subsequently raised to $20^{\circ} \mathrm{C}$ for another $2 \mathrm{~h}$. To count viable bacterial cells in the hFMT powder for quality purposes, $50 \mu \mathrm{l}$ from a stock of $0.5 \mathrm{~g}$ hFMT powder was diluted in $4.5 \mathrm{~mL}$ MRD, streaked out on nonselective agars (horse blood agar for total aerobic bacteria and anaerobic blood agar for total anaerobe bacteria) as well as on agars selective for lactobacilli (Man, Rogosa and Sharpe broth (MRS) agar) and for bifidobacteria (MRSx agar). Agars were incubated overnight at $37^{\circ} \mathrm{C}$ or for $48 \mathrm{~h}$ in the case of MRSx agar; conditions were aerobic (horse blood agar and anaerobic blood agar) or anaerobic conditions (MRS and MRSx), respectively. The resulting powder was aliquoted into small vials to $0.125 \mathrm{~g}$ final content and shipped to the University Hospital Essen.

\section{Mouse fecal sample collection}

Individual fecal pellets from mice were collected after three treatment gavages but before any immunizations with hTSHR or Bgal (baseline), and after four gavages but before the third immunization (mid-timepoint). The contents of colon or entire intestines were collected for metataxonomic analysis after the sacrifice of the mice (6 weeks after the last immunization and nearly 9 weeks after the last gavage).

\section{DNA extraction and sequencing}

DNA was extracted using the QiAmp Fast DNA Stool Mini kit (Qiagen Ltd, West Sussex, UK). Collected samples were individually placed in 2-mL tubes prefilled with $0.1 \mathrm{~mm}$ silica and zirconia bead mix (Benchmark Scientific, Edison, USA), dissolved in $1 \mathrm{~mL}$ InhibitEX buffer (Qiagen Ltd, West Sussex, UK) and vortexed until homogenized. A bead-beating step (Beadbug microcentrifuge homogenizer, Benchmark Scientific, USA) was applied for $3 \times 60 \mathrm{~s}$ at $5 \mathrm{~m} / \mathrm{s}$ with 5 -min rest in between. Total genomic DNA was eluted in sterile microcentrifuge tubes and quantified by Qubit Fluorimetric Quantitation (ThermoFisher Scientific Ltd, UK) as per manufacturer's instructions. Metataxonomic sequencing (16S rRNA gene sequencing) was performed at Research
\& Testing RTL Genomics (Lubbock, TX, USA), using primers detecting the V1-V2 regions of the 16S rRNA gene plus bifidobacteria regions to generate 10,000 paired-ends reads on a Illumina MiSeq (Illumina, San Diego, USA.

\section{Processing of sequencing reads}

A first quality check on raw demultiplexed paired-end sequences (R1 and R2) was done using FastQC. All of the below steps were performed with the quantitative insights into microbial ecology (QIIME) 1.9 open-source bioinformatics pipeline for microbiome analysis [32]. Joining of paired-end sequences was done using the function "multiple_join_paired_end.py", with the SeqPrep method (https://github.com/jstjohn/SeqPrep). Quality filtering of the reads was performed according to the following parameters: (i) maximum of three consecutive low-quality base calls (Phred $<19$ ) allowed and (ii) fraction of consecutive high-quality base calls (Phred $>$ 19 ) in a read over total read length $>=0.75$; iii) no " $\mathrm{N}$ "labeled bases (missing/uncalled) allowed. A total of 13, 782,107 reads were obtained before quality filtering including also the small intestines samples. The reads per group were as the following: $\mathrm{ddH}_{2} \mathrm{O} 2,593,620$; hFMT 2, 972,296; Lab4 2,102,509; vancomycin 5,280,854 and GO patients $483,510(n=6$, i.e. reads were sequenced in a separate run with the same primers and were processed together with mouse reads processing using QIIME and unknown 349,318). Reads were reduced to a total of 12 , 884,785 after quality filtering (reads per group: $\mathrm{dd}_{2} \mathrm{O} 2$, 418,786; hFMT 2,757,051; Lab4 1,945,969; vancomycin 5,003,546; GO patients 428,852 and unknown 330,581). Passing-filter reads were aligned against the SILVA 123 reference database using the "pick_closed_reference otus.py" approach for taxonomic assignment with a 97\% cluster identity [33]. Operational taxonomic unit (OTUs) with total counts lower than 15 in fewer than 2 samples were filtered out. To correct potential biases in library size due to sampling procedures or sequencing depth, OTUs were normalized in each library through the cumulative sum scaling (CSS) [34] implemented in the "normalized_table.py" function. Filtered and normalized OTUs were collapsed into each phylogenetic level (from phylum to genus) using the function "taxa_summary.py".

\section{Serological analysis of mouse blood}

Anti-TSHR antibodies (TRAbs) and TSH-stimulating antibodies (TSAbs) and total T4 were evaluated in mouse serum [27, 35]. Therefore, TRAbs were measured in commercial TRAK kits using $25 \mu \mathrm{l}$ serum plus $75 \mu \mathrm{l}$ human control serum as TSH binding inhibitory immunoglobulins activity in competition with labeled bTSH to the human TSHR (ThermoFisher, BRAHMS, Germany). TSAbs were measured in $3 \mu \mathrm{l}$ serum plus $147 \mu \mathrm{l}$ buffer 
in a bioassay using stably transfected mouse TSHRChinese hamster ovary cells $(\mathrm{CHO})$ cells kindly provided by Sandra McLachlan [29, 30]. TSHR-CHO cells were incubated with test sera diluted 1:20 in Ham's F12 supplemented with HEPES $10 \mathrm{mM}(\mathrm{pH}$ 7.4) and isobutylmethylxanthine $1 \mathrm{mM}$ in 96-well plates for $80 \mathrm{~min}$ at $37^{\circ} \mathrm{C}$. Intracellular cAMP was extracted with ethanol after aspirating the medium, evaporated to dryness and resuspended in Dulbecco's PBS. The concentration of TSAbs is directly correlated to the cAMP production of the cells. cAMP concentration in $100 \mu \mathrm{l}$ of the mouse TSHR-CHO cells supernatants was measured by ELISA (Enzo, Farmingdale, NY, USA). Total T4 concentrations were measured in $25 \mu \mathrm{l}$ serum by ELISA (DRG, Springfield, NJ, USA).

\section{Histopathology of thyroid glands and orbits}

The thyroids were formalin fixed and paraffin embedded, and sections $(1 \mu \mathrm{m}) \mathrm{H} \& \mathrm{E}$ stained. Thyroidal morphology was blindly evaluated by two different observers and indexed as hyperactive, heterogeneous or normal in comparison to the thyroid morphology of the respective $\beta$ gal mice. Hyperplastic glands (indicating hyperthyroidism) were characterized by increased total size, cuboid cylindrical follicular cells with minimal colloid and thick follicular epithelium. Numbers of mice displaying normal, heterogeneous or hyperactive thyroid morphology are given in \%. The orbits were formalin fixed and paraffin embedded. Orbital slices $(1 \mu \mathrm{m})$ at the anterior, middle and posterior area of the mouse orbits were $H \& E$ stained and examined. Quantification of adipose tissues and muscle atrophy in extraocular inferior rectus and medial rectus muscle was performed with ImageJ. The area of adipose tissue was normalized to the optic nerve area. Atrophic cells were identified by diameter $(<$ $50 \mu \mathrm{m})$ and round shape of muscle fibers [27, 35]. Images were generated using an Olympus BX51 microscope.

\section{Analysis of lymph node T cell subsets by flow cytometry} Draining lymph nodes of mouse orbits were harvested and teased apart into a single-cell suspension by mashing tissue between two frosted microscope slides. Collected cells were filtered using a $100-\mu \mathrm{m}$ cell strainer to eliminate clumps and before centrifuging $5 \mathrm{~min} 400 \times g$ at $4{ }^{\circ} \mathrm{C}$. Cell pellet was then resuspended in $1 \mathrm{ml}$ of PBS with $2 \%$ FBS to count and evaluate cell viability. Appropriate volumes of each sample equal to $2 \times 10^{6}$ cells were transferred to new tubes for staining. Antibody mix of CD4 FITC, CD8PE and CD25 APC (all from BioLegend) was added to each sample and added up to $100 \mu \mathrm{l}$ using PBS with $2 \%$ FBS. Cells were incubated for at least $30 \mathrm{~min}$ at $2-8^{\circ} \mathrm{C}$ before washing and spinning down at $400 \times g$ for $5 \mathrm{~min}$. Cells were resuspended in $300 \mu \mathrm{L}$ of
PBS with 2\% FBS and subjected to read by flow cytometry.

\section{Measurement of circulating cytokines in mouse serum}

CCL5, IL-4, CCL20, IFN- $\gamma$, IL-2, IL-6, IL-10, IL-17/IL$17 \mathrm{~A}$ and TNF-alpha in murine sera were measured by polystyrene bead-based Luminex technology (R\&D Systems, Minneapolis, USA) according to the manufacturer's instructions, and the assay was run on a Luminex 200 instrument (Luminex Corporation, Austin, TX, USA).

\section{Statistical analysis}

Results are presented as mean \pm standard error of the mean. Multiplicity adjusted $P$ values are marked as follows: ${ }^{*} \leq 0.05 ;{ }^{* *} \leq 0.01 ;{ }^{* * * *} \leq 0.001 ;{ }^{* * * *} \leq 0.0001$. Changes between mouse groups with $P$ values $>0.05$ are regarded as not statistically significant and are not marked in the graphs. Additionally, the upper $99 \%$ confidence interval (CI) of the control Bgal group was defined as the threshold for positivity of individual mice and is indicated by a dotted line when appropriate. In order to compare the total outcome between the groups, we combined the key parameters of either autoimmune hyperthyroidism (TSAbs and T4) or orbitopathy (brown adipose tissue (BAT) and atrophic fibers) by using the Z-score method. The standard score (Z-score) was used to compare results from different mouse groups normalized to the mean value of the total mouse population (reference population). The Z-score values (arbitrary units) represent the values of standard deviation from the mean value of the reference population. We also categorized severity of induced disease: Subclinical disease $(Z$-score $<0)$ : These mice did not develop significant autoimmune hyperthyroidism and/or GO. Clinical disease (Z-score $>0$ ): These mice displayed signs of overt disease during the experiment. Clinical disease is classified in accordance with Zscore values as mild ( $Z$-score $0>1$ ) or moderate-to-severe (Z-score $>1$ ). The number of mice is given in \%. Bacterial counts data were Box-Cox transformed before statistical analysis [36]. Otherwise stated, statistical analyses for $16 \mathrm{~S}$ rRNA gene sequencing data were performed in R v3.4.1. Alpha- and beta-diversity indices were obtained from the filtered OTU-table in QIIME. Kruskal-Wallis and pairwise Wilcox-test with Benjamini-Hochberg (BH) adjustment for multiple corrections were used to test the association between alpha-diversity indices and variables (e.g. immunizations, treatments or microbiota sources). Dissimilarities amongst groups (treatments/immunizations) or pairwise dissimilarities along variables were evaluated non-parametrically using the permutational analysis of variance approach (PERMANOVA) with 999 permutations [37], implemented in the $\mathrm{R}$ Vegan package. When necessary, a stratification of the permutations was applied 
to correct for the different microbiota sources sampled (e.g. entire and colon samples). Differential abundant taxonomies were identified using a linear regression model. Random forest (RF) was employed to classify samples either amongst treatments $\left(\mathrm{ddH}_{2} \mathrm{O}, \mathrm{hFMT}\right.$, Lab4 or vancomycin) or between immunizations ( $\beta$ gal or TSHR) based on their microbiota composition and to identify genera driving the classification (variable importance). Correlations between disease features and bacterial biomarkers were assessed using the Pearson's correlation coefficient $(r)$, using the Corrplot R package. The extent of the hFMT between donors and recipients-or engraftment [38] —-was calculated using the SourceTracker R package [39]. A detailed description of the methods performed is available in Additional Methods.

\section{Results}

The mouse cohort comprised four groups receiving different treatments: (i) vancomycin antibiotic; (ii) Lab4 probiotic consortium (2 strains of Lactobacillus acidophillus, 1 strain Bifidobacterium animalis, 1 strain Bifidobacterium bifidum); (iii) freeze-dried human fecal material (hFMT) from 6 severe GO patients; (iv) ddH2O as control, as described in Fig. 1a. Pups were gavaged with either Lab4 or hFMT or $\mathrm{ddH}_{2} \mathrm{O} 1$ day after birth, at weaning, and before and in the middle of immunizations whereas dams and their pups (from birth) received vancomycin in their drinking water throughout the experiment.

\section{Early-life manipulation treatments conferred enduring changes of the TSHR-immune lower gastrointestinal microbiota}

At the end of the experimental procedure (Fig. 1a), 9 weeks after the last gavaged treatment, the microbiota was sampled and analysed via 16S rRNA gene sequencing, from the large intestines in vancomycin, hFMT and $\mathrm{ddH}_{2} \mathrm{O}$ groups. The gut microbiota was obtained from the entire intestine of Lab4-treated and a related group of $\mathrm{ddH}_{2} \mathrm{O}$-receiving mice. A total of 3623 OTUs with more than 15 counts in at least two samples were retrieved from quality-filtered reads and used in further analyses. There were no significant differences in alphaand beta-diversity indices between the entire and the large intestines (Figure S1A-B); therefore, data from the two anatomical sources were combined and referred to as lower gastrointestinal tract (LGI) microbiota.

Vancomycin-treated LGI microbiota had drastically reduced richness and diversity compared to $\mathrm{ddH}_{2} \mathrm{O}$, hFMT and Lab4 mice, in both TSHR and $\beta$ gal-immunized mice (Fig. 1b and S1C, respectively). Firmicutes-prevalent genera such as Faecalibacterium, Eubacterium, Ruminiclostridium and Ruminococcaceae spp. were depleted from vancomycin LGI microbiota in both TSHR (Figure S2) and Bgal mice (Figure S3), whilst Bacteroides spp. showed the highest counts compared to $\mathrm{ddH}_{2} \mathrm{O}-$, Lab4 -and hFMT-TSHR-immunized mice. Potential vancomycinresistant bacteria were present, including Proteobacteria genera Enterobacter, Salmonella, Pseudomonas spp. and E. coli. Interestingly, Verrucomicrobia genus Akkermansia increased in TSHR compared to $\beta$ gal vancomycin-treated mice $(P=0.011$, Fig. 1c). The unique vancomycin microbiota composition facilitated $100 \%$ per-class prediction accuracy (19/19) using the random forest algorithm with 10, 000 decision trees, to predict early-life treatments in endpoint samples' genus-level gut microbiota (Fig. 1d-g).

TSHR-Lab4 mice showed a lower equitability index compared to TSHR-ddH ${ }_{2} \mathrm{O}$ mice $(P=0.045$, Fig. $1 \mathrm{~b})$. Differentially abundant genera were observed after Lab4 administration, with twelve genera showing increased or decreased relative abundance when compared with TSHR-ddH ${ }_{2} \mathrm{O}$ mice (data not shown). In contrast to the vancomycin treated mice, Akkermansia spp. decreased in TSHR-Lab4 compared to Bgal-Lab4 $(P=0.040$, Fig. 1c).

Bacteria in the hFMT powder were viable (Figure S4A). TSHR-hFMT had reduced Shannon diversity compared to TSHR-dd $\mathrm{H}_{2} \mathrm{O}$ mice $(P=0.019$, Fig. $1 \mathrm{~b})$, whilst no significant differences occurred in $\beta$ gal mice (Figure S1A). At genus level, TSHR-hFMT mice showed significantly lower Bacteroides spp. counts compared to $\mathrm{ddH}_{2} \mathrm{O}(P=0.003$, Figure S2). Following pairwise comparison, sixteen genera were differentially abundant compared to the TSHR- $\mathrm{ddH}_{2} \mathrm{O}$ group (data not shown). Bacteroides spp. were significantly reduced in hFMTTSHR compared to hFMT- $\beta$ gal mice $(P<0.001$, Fig. 1 c $)$, as previously reported [25] and between GO patients and healthy controls (Figure S4B-D).

Differences in the Lab4 and hFMT LGI microbiota composition were sufficient for predicting treatment with per-class accuracies of $70 \%(14 / 20)$ and $74 \%(14 /$ 19), respectively. In contrast, the $\mathrm{dd}_{2} \mathrm{O}$ group had a per-class accuracy of $50 \%(10 / 20$, Fig. $1 d$, e). In predicting the immunizations, including all treatments, the $\beta$ gal group showed a $63 \%$ per-class accuracy (22/35 samples), whilst 77\% per-class accuracy for the TSHR (33/43, Fig. 1f, g). Similar outcomes were retained when repeating the model without the vancomycin-treated group (Figure S1D-G).

\section{Combined effect of treatments, immunizations and time} on the fecal microbiota composition of GO mouse model We assessed the impact of various treatments over time by analysing the fecal microbiota after gavage but prior to any immunization (baseline) and following 3 gavages but before the third immunization (midpoint) (Fig. 1a). At baseline, vancomycin treatment already produced drastic effects, comparable to those reported at the end of the experiment (Figure S5A). Compared to $\mathrm{ddH}_{2} \mathrm{O}$ controls, Lab4 increased both Chao1 (Figure S5A) and 

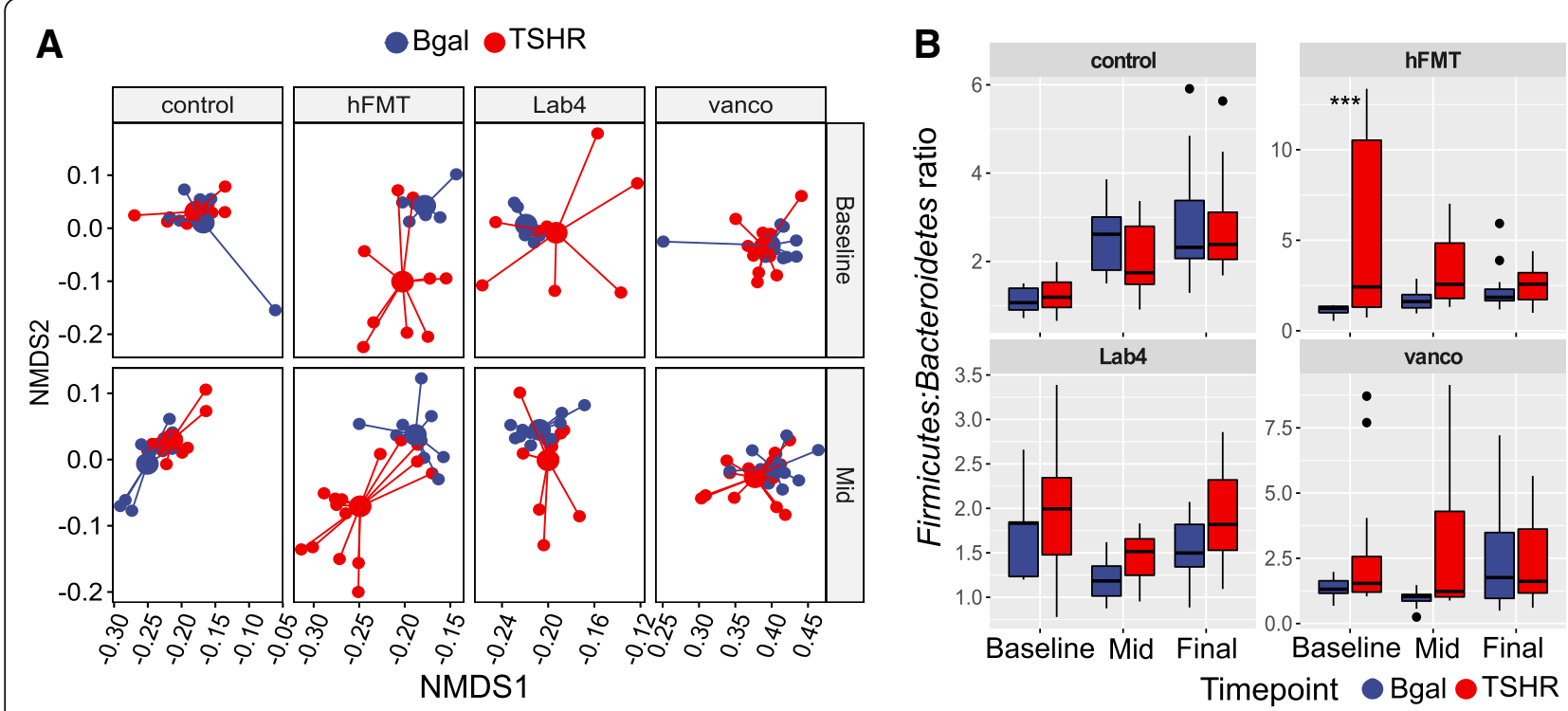

C

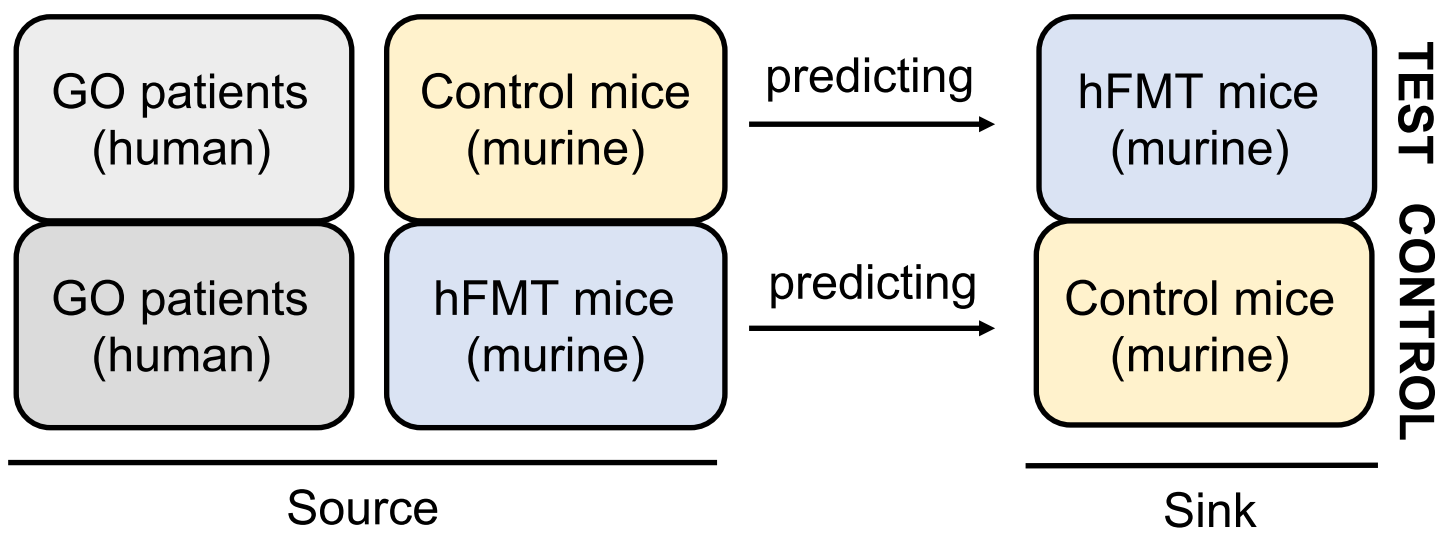

D

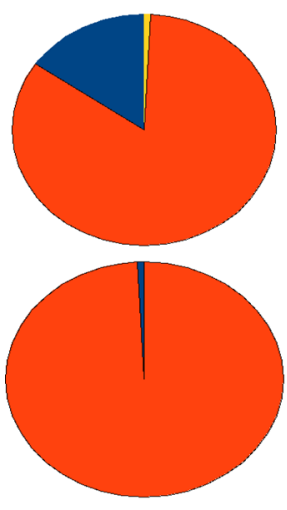

Baseline

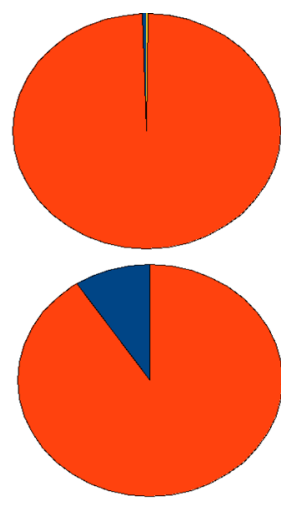

Mid

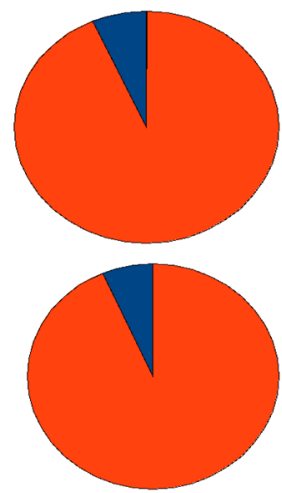

Final
$\%$ predicted:

human

murine

unknown

Fig. 2 (See legend on next page.) 


\section{(See figure on previous page.)}

Fig. 2 Effect of treatments, immunizations and time on the GO model gut microbiota. a Differences between immunizations at each timepoint and per treatment. PERMANOVA with 999 permutations, ${ }^{* *} P=0.008$ and ${ }^{* *} P=0.016$ ( $\mathrm{n}$ mice/treatment/immunization at baseline: control TSHR $=10, \beta \mathrm{gal}=6$; $\mathrm{hFMT-TSHR}=9$, $\beta \mathrm{gal}=6$; Lab4 TSHR = 9, $\beta \mathrm{gal}=5$; vancomycin TSHR $=12, \beta \mathrm{gal}=8)$ ( $\mathrm{n}$ mice/treatment/immunization at midtimepoint: control TSHR = 11, $\beta \mathrm{gal}=9$; hFMT-TSHR $=5$, $\beta \mathrm{gal}=9$; Lab4 TSHR $=11, \beta \mathrm{gal}=11$; vancomycin TSHR $=14, \beta \mathrm{gal}=4)$. $\mathbf{b}$ Firmicutes to Bacteroidetes ratio comparing immunizations in each timepoint and within each treatment group. Welch's $t$ test with $\mathrm{BH}$ correction: ${ }^{* *} P=$ 0.0006. c Rationale of the SourceTracker analysis (see STAR methods). Human GO donors $(n=6)$, murine controls ( $n$ control/timepoint: baseline $=$ 16 , mid $=20$, final $=20$ ) and hFMT-receiving mice ( $n$ hFMT/timepoint: baseline $=15$, mid $=24$, final $=19$ ). $\mathbf{d}$ Pie charts: engraftment expressed as average \% probability using the control and the test analysis in each timepoint. Unknown: observations not assigned to a specific source at the significant threshold $(a=0.001)$

observed OTUs indices, whilst hFMT reduced bacterial diversity (Shannon) and evenness, but did not reach significance. Lab4- and hFMT-treated mice displayed differences in fecal microbiota composition compared to $\mathrm{ddH}_{2} \mathrm{O}$ - and vancomycin-treated mice (i.e. reduced counts of Bacteroides spp.), but the two groups differed very little at baseline (Figure S5B). A significant difference in the Firmicutes to Bacteroidetes ratio was observed between TSHR and $\beta$ gal immunizations in the hFMT-receiving mice ( $P=0.0006$, Fig. $2 b)$. Similarity between hFMT-receiving mice and the GO human donors (Fig. 2c) was calculated with the SourceTracker algorithm [39] using the family-level microbiota composition. At baseline, 4 out of 15 hFMT-receiving mice fecal samples (test) showed more than $40 \%$ similarity (min $46 \%$, max $72 \%$ ) with the GO donors' source, whilst none out of $16 \mathrm{ddH}_{2} \mathrm{O}$-receiving mice (control) shared any similarity with the GO donors samples (Fisher's exact test with Yates' continuity correction, $P<0.001$; Fig. 2 d).

At midpoint, diversity and evenness (but not richness) of the vancomycin-treated gut microbiota further reduced compared to baseline. Conversely, richness indices significantly increased between baseline and midpoint in TSHR-hFMT mice $(P=0.023$ observed OTUs and $P=0.019$ Chao1, respectively), as in the $\mathrm{ddH}_{2} \mathrm{O}$ group $(P=0.014$ observed OTUs and $P=0.0038$ Chao1; Figure S5C). Bray-Curtis-based non-metric dimensional scaling (NMDS) separation between hFMT and Lab4 mice (considering the two immunizations together) was significant (Fig. 2a).

No significant differences in beta-diversity were observed between TSHR and $\beta$ gal immunizations at baseline, except in the hFMT-treated mice $(P=0.008)$. which lasted at the midpoint $(P=0.016$, Fig. 2a). Centroids (sampling distribution of the mean) of each immunization were close to each other, replicating our previous findings at the equivalent T2 timepoint (Masetti et al., 2018). Bacteroides spp. significantly increased with time in Lab4 mice, in both immunizations (data not shown). At midpoint, none of the hFMTreceiving mice $(0 / 24)$ showed any similarity with the human donors $(P<0.001)$ whilst half of the $\mathrm{ddH}_{2} \mathrm{O}$ mice $(10 / 20)$ showed $>10 \%$ similarity of the gut microbiota with GO donors (Fig. 2d). At the end of the experiment, the same similarity to human donors was observed in both murine controls (26\%) and hFMT-receiving colon samples (26\%).

\section{Influence of gut microbiota modifications on TSHR directed autoimmunity}

Antibodies to the human TSHR were measured by Thyrotropin binding inhibiting immunoglobulins (TBII; TRAb) and were significantly detected in all TSHRimmunized mice, but not in $\beta$ gal- $\mathrm{dd}_{2} \mathrm{O}$ mice $(P \leq$ 0.0001), indicating successful immunization (Fig. 3a). Thyroid-stimulating antibodies (TSAb) were measured using a mouse TSHR overexpressing $\mathrm{CHO}$ cell-based bioassay. $\mathrm{ddH}_{2} \mathrm{O}-$, Lab4- or hFMT-treated TSHRimmunized mice showed a statistically significant induction of TSAb compared to respective $\beta$ gal mice $(P \leq$ 0.0001 ) but not in the vancomycin-treated group (Fig. 3b). We also quantified percentages of mice developing significant TSAB based on the upper $99 \%$ CI of the respective Bgal mouse group as the positive threshold (Table S2). Eighty-four percent of TSHR-ddH $\mathrm{H}_{2} \mathrm{O}$ mice developed significant TSAB; treatment with Lab4 or hFMT increased positivity to $90 \%$ and $100 \%$, respectively, but vancomycin treatment reduced TSAB to $64.3 \%$ of mice (Table S2).

Disease features were correlated with the bacterial biomarkers identified by the two random forest models by Pearson's correlation coefficient. In TSHR-dd $\mathrm{H}_{2} \mathrm{O}$, six genera including Parabacteroides counts correlated positively with TRAbs. Positive correlations were also observed between TRAB and counts of unidentified/ uncultured Firmicutes in TSHR-vancomycin mice and with Parabacteroides in TSHR-hFMT. Negative correlations were seen in TSHR-hFMT mice between TRAB and Lactobacillus and in TSHR-Lab4 between TSAB and uncultured Firmicutes, Lachnoclostridium and uncultured Bacteroidetes (Figure S6) and a strong negative correlation with the genus Lactobacillus.

\section{Effect of microbiome modification on thyroid function}

Total T4 values tended to increase in TSHR-immunized groups, with Lab4-treated showing significantly higher T4 compared to the corresponding $\beta$ gal $(P \leq 0.05)$ (Fig. $3 c)$. Based on the $99 \%$ CI of the relevant $\beta$ gal- 

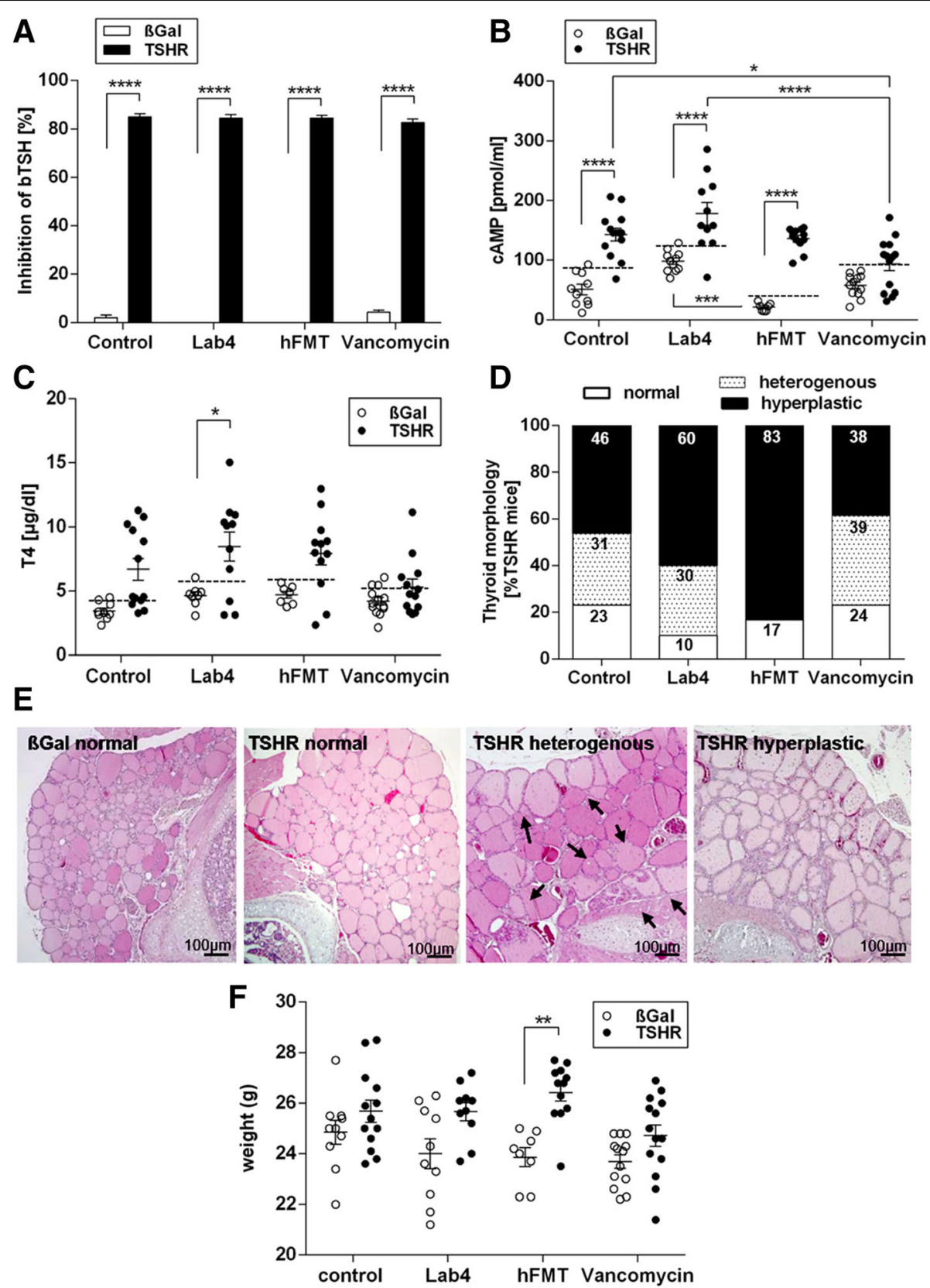

Fig. 3 Mouse TSHR antibody evaluation and impact of gut microbiome modification on thyroid function and morphology. a Total TSHR antibodies (TRAbs) were measured by TSH binding inhibitory immunoglobulin activity to the human TSHR given as \% inhibition of bTSH. $\mathbf{b}$ Thyroid-stimulating autoantibodies (TSAbs). Stimulating activity is given in CAMP (pmol/mL). Data are presented as mean \pm standard error of the mean. Multiplicity adjusted $P$ values are marked as follows ${ }^{* * *} P<0.0001,{ }^{* *} P<0.001,{ }^{*} P<0.05$ (two-way ANOVA). c Total T4 values ( $\mu \mathrm{g} / \mathrm{dl}$ ) in Bgal- and TSHR-immunized mice from each treatment group ${ }^{*} P<0.05$. $\mathbf{d}$ H\&E of thyroid slices for thyroid morphology evaluation (in normal, heterogeneous (hetero) or hyperthyroid (hyper)). e Representative thyroid images at $\times 20$ magnification. Heterogeneous thyroids contained normal and hyperthyroid regions (indicated by arrows). $\mathbf{f}$ Weights of animals at the endpoint of the experiment. Data are presented as mean \pm standard error of the mean. Multiplicity adjusted $P$ value is marked as ** $P<0.01$ (two-way ANOVA)

immunized mice, $66.7 \%$ of TSHR- $\mathrm{ddH}_{2} \mathrm{O}$ mice had elevated T4 levels which increased to $73 \%$ and $75 \%$ in Lab4- or hFMT-treated respectively but reduced to $36 \%$ in vancomycin mice (Table S2). Histological examination of the thyroid revealed variable hyperplastic morphology (thickened epithelium, reduced colloid) indicating gland hyperactivity in TSHR-immunized mice but not in the Bgal groups (Fig. 3d, e). Some thyroids had heterogeneous morphology with normal regions and areas of hyperplastic follicles (Fig. 3e, arrows). Hyperplastic/ 
A

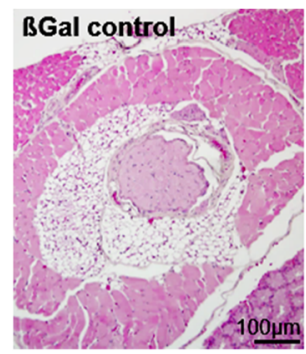

C
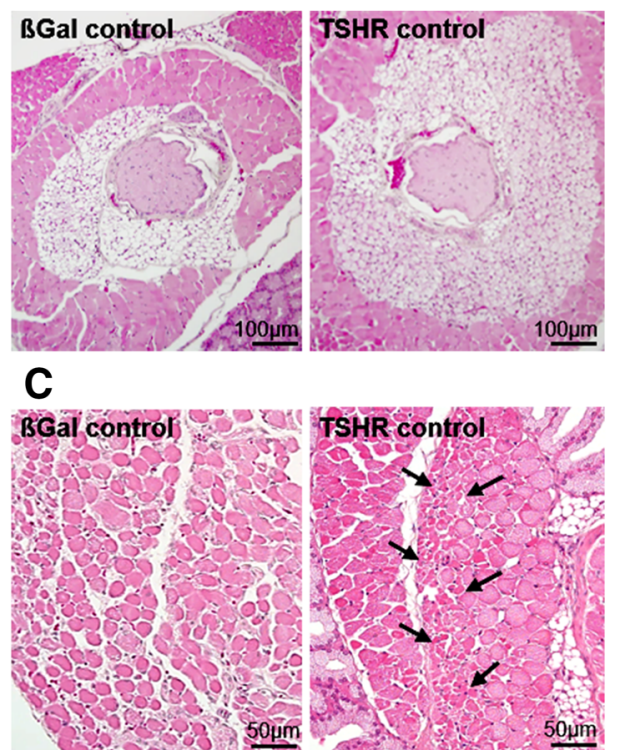

B

\section{D}
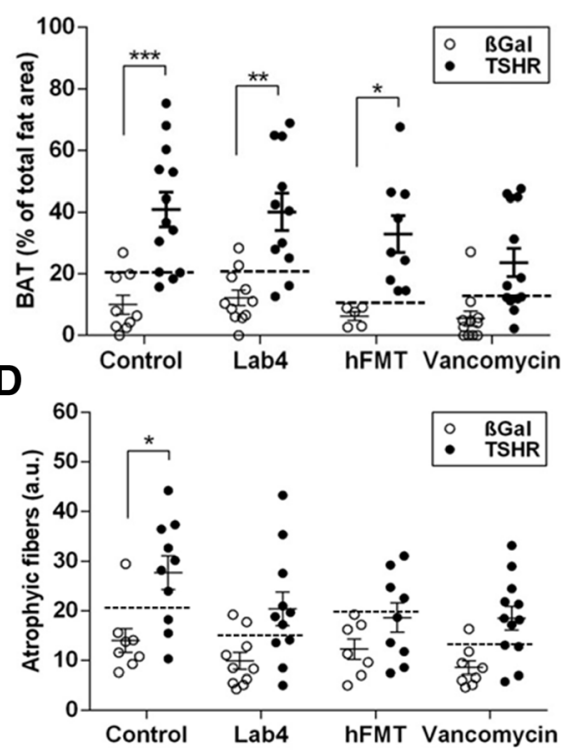

Fig. 4 Gut microbiome modification modulates orbital tissue abnormalities in GO mouse model. The orbits of mice were fixed, paraffin embedded, and consecutive slices of the middle orbital area were stained with H\&E and evaluated for a brown adipose tissue (BAT); representative images are shown, magnification $\times 10$. b BAT as the percentage of the total fat area. $\mathbf{c}$ Atrophic fibers in extra orbital muscles; representative images are shown, magnification $\times 20$, arrows indicate areas with atrophic fibers. $\mathbf{d}$ atrophic fibers/total muscle fiber area (a.u.). Data are presented as mean \pm standard error of the mean. Multiplicity adjusted $P$ values are marked as ${ }^{* * *} P<0.001,{ }^{* *} P<0.01,{ }^{*} P<0.05$ (two-way ANOVA)

heterogeneous morphology was found in $46 \%$ and $31 \%$ respectively, of TSHR-ddH $\mathrm{H}_{2} \mathrm{O}$ mice (Fig. 3d). Lab4 and hFMT increased hyperplastic thyroid to $60 \%$ and $83 \%$, respectively (Fig. 3d). The hFMT morphology paralleled their increased TSAb and elevated T4 levels when compared with other groups (Table S2). In contrast, vancomycin reduced hyperplastic thyroids to $38 \%$ with $39 \%$ having heterogeneous morphology, suggesting milder hyperactivity of the gland compared to other mice (Fig. 3e, Table S2). In addition, weights of hFMT-treated TSHR-immunized mice were significantly increased compared to ßgal-immunized mice (Fig. 3f).

TSHR-ddH $\mathrm{H}_{2} \mathrm{O}$ mice showed positive correlations between T4 and the same three Firmicutes genera correlating with TSAB. Positive and negative correlations were observed between T4 and Lachnoclostridium and the genus Ruminiclostridium in vancomycin- and Lab4treated, respectively (Figure S6).

Microbiome modification modulates Graves' orbitopathy Individual TSH-immunized mice developed eye signs, e.g. proptosis and inflammation, indicating orbitopathy to different degrees which were difficult to quantify objectively (Suppl. Figure S7A). To determine the impact of gut microbiome modification on orbitopathy, histological sections of mice orbits were analysed. We have previously shown that the mouse orbit contains TSHR- positive brown adipose tissue (BAT) which is enlarged in the GO model [40-42]. Orbital BAT is characterized by small fat lobules and can be distinguished from orbital white adipose tissue (Fig. 4a, Suppl. Figure S7B). In agreement with our earlier studies, BAT area increased in the orbital tissue of TSHR-ddH $\mathrm{H}_{2} \mathrm{O}$ mice (69\% positive mice based on $99 \% \mathrm{CI}$ ) compared to $\beta$ gal- $\mathrm{ddH}_{2} \mathrm{O}$ mice $(P \leq 0.001$; Fig. $4 \mathrm{~b})$. Enlargement of BAT was enhanced in TSHR-immunized mice treated with Lab4 ( $P \leq 0.01 ; 81.8 \%$ positive mice) or hFMT (100\% positive mice). In contrast, vancomycintreated TSHR-immunized mice had a much lower portion of BAT positive mice (53.8\%) compared to the other TSHR-immunized mouse groups (Table S2). Previously, we described muscle atrophy (smaller muscle fibers, Fig. 4c arrows) as another feature of orbitopathy in TSHR-immunized mice [27]. Significant muscle fiber atrophy was detected in TSHR$\mathrm{dd}_{2} \mathrm{O}$ mice compared to $\beta$ gal-dd $\mathrm{H}_{2} \mathrm{O}$ group $(P \leq$ 0.05 ) and not in the other three groups (Fig. $4 \mathrm{~d}$ ). Based on $99 \% \mathrm{CI}, 70 \%$ of $\mathrm{TSHR}-\mathrm{ddH}_{2} \mathrm{O}$ mice developed significant muscle atrophy whilst $63.6 \%$ of Lab4-, $44.4 \%$ of hFMT- or $66.7 \%$ of vancomycintreated TSHR-immunized mice had some muscle atrophy (Table S2). However, lymphocytic infiltrations were not detected in the orbital tissues (Suppl. Figure S7C, D). 

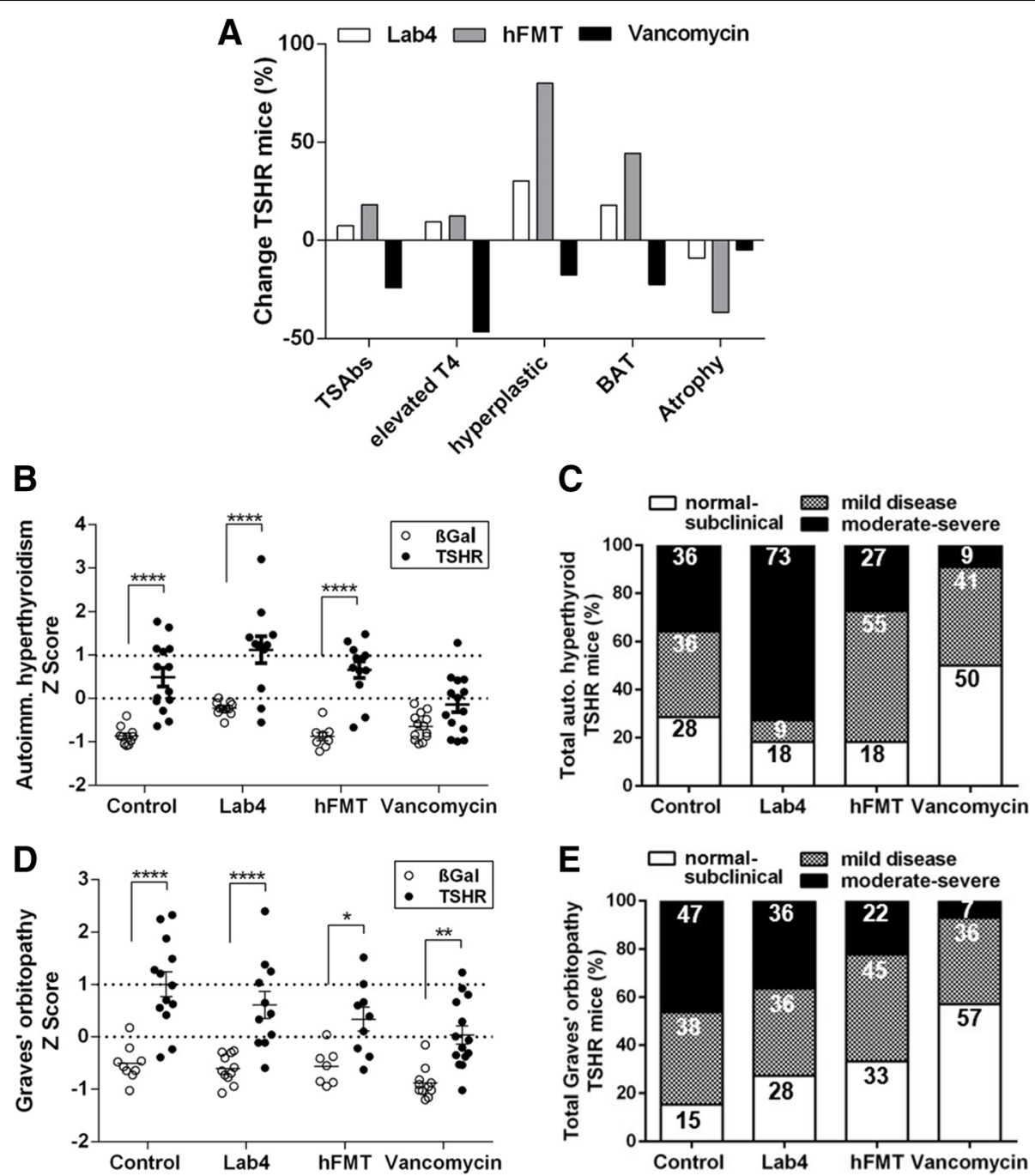

Fig. 5 Impact on autoimmune hyperthyroidism and orbitopathy and total disease outcomes of gut microbiota modifications. a Percentages of positive untreated TSHR-immunized mice set to $100 \%$ and the changes of positivity in the treated groups Lab4, hFMT or vancomycin were calculated. Changes in positive mice are given in \% relative to untreated TSHR-immunized mice. Parameters were normalized using the Z-Score (see the "Materials and methods" section). b Z-Score of autoimmune hyperthyroidism includes values of TSAbs and T4. c Z-Score of orbitopathy evaluated by BAT and atrophic fibers. Data are presented as mean \pm standard error of the mean. Statistical analysis was performed by two-wayANOVA; multiplicity adjusted $P$ values are given as follows: ${ }^{*} P \leq 0.05 ;{ }^{* *} P \leq 0.01 ;{ }^{* *} P \leq 0.001$; ${ }^{* * *} P \leq 0.0001$. $\mathbf{d}$, e Disease classification was based on Z-score values. The number of mice is given in \%, see STAR methods for classification parameters. Additionally, the number of mice in each category is shown in Table S2

In the vancomycin-treated TSHR-immunized group, a strong negative correlation was observed between the total adipose value, BAT and the Akkermansia spp. and between Bacteroides spp. and the total adipose tissue whilst a positive correlation was observed between Lachnoclostridium counts and BAT. In Lab4TSHR, atrophy correlated negatively with Lachnoclostridium spp. and uncultured Firmicutes as well as uncultured Bacteroidetes, whilst Akkermansia spp. correlated negatively with the total adipose tissue (Figure S6).

\section{Modification of the gut microbiome affects disease} features to varying degree

To compare the effects of the various microbiota modification treatments on characteristic disease features, the percentages of mice positive for TSAbs, elevated T4, hyperplastic thyroid morphology, BAT and muscle atrophy of each TSHR-immunized mouse group were evaluated based on the upper 99\% CI of the respective $\beta$ gal mouse group (Table S3). Percentages of positive TSHR-ddH $\mathrm{H}_{2} \mathrm{O}$ mice were set to $100 \%$ and the relative changes of positivity in the treated groups were calculated (Fig. 5a). 

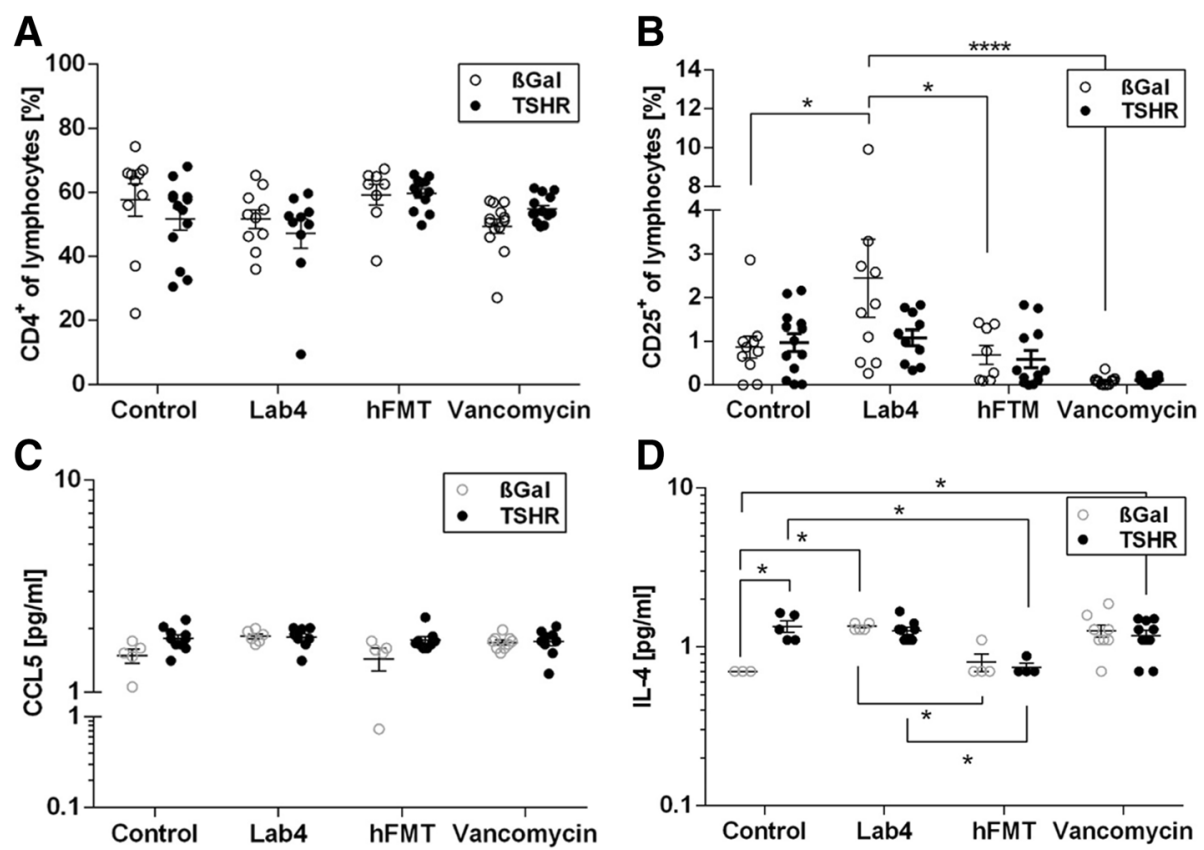

Fig. 6 Effects of gut microbiome modification on lymph node T cell subsets, cytokine and chemokine levels. a CD4 ${ }^{+}$and $\mathbf{b} C D 25^{+} \mathrm{T}$ cell population from draining lymph nodes of TSHR- and Bgal-immunized mice in each treatment group. Data are presented as mean \pm standard error of the mean. Multiplicity adjusted $P$ values are marked as ${ }^{* * *} P<0.0001,{ }^{*} P<0.05$ (two-way ANOVA). c CCL5 and $\mathbf{d} I L-4$ circulating chemokines/cytokines from sera. Cytokine values are log10 transformed. Multiplicity adjusted $P$ values are marked as $* P<0.05$ (two-way ANOVA).

Lab4 and hFMT, both increased the percentage of mice positive for TSAb, elevated total serum T4 and orbital BAT enlargement, but reduced mice with orbital muscle atrophy. hFMT also strongly increased percentages of mice with hyperplastic thyroid morphology. Vancomycin reduced the percentage of mice positive for TSAb, elevated T4, hyperplastic morphology and orbital BAT whilst orbital atrophy was only mildly affected (Table S2 and Fig. 5a).

\section{Modification of gut microbiome determines the total outcome of disease}

The differently treated TSHR-immunized mouse groups developed autoimmune hyperthyroidism or orbitopathy to varying degrees. To compare total disease outcome between the mouse groups, we normalized and combined the different parameters for each mouse by the Zscore method as described earlier [27, 35, 42]. As shown in Fig. 6, the TSHR-ddH $\mathrm{H}_{2} \mathrm{O}$ mouse group (Z-score $>0$ ) can be clearly separated from $\beta$ gal mouse group (Z-score $0)$ concerning autoimmune hyperthyroidism $(P \leq$ $0.0001)$ and orbitopathy $(P \leq 0.0001)$ (Fig. 5b, c). Thus, TSHR-dd $\mathrm{H}_{2} \mathrm{O}$ mice manifested significant overt disease (termed clinical disease). Z-score values between 0 and 1 were defined as mild disease and Z-scores $>1$ were regarded as moderate-to-severe disease as described previously [42]. TSHR-immunized mice with Z-score $<0$ were classified as normal-to-subclinical disease, i.e. have only developed TSHR antibodies (Fig. 5b). Numbers of mice showing normal-to-subclinical, clinical, mild or moderate-to-severe disease are given in Table S3. Overall, hFMT and Lab4 increased the incidence and severity of autoimmune hyperthyroidism whereas vancomycin treatment led to mild or no disease compared with TSHR-dd $\mathrm{H}_{2} \mathrm{O}$ (Fig. 5d). Regarding orbitopathy, $85 \%$ of TSHR-dd $\mathrm{H}_{2} \mathrm{O}, 72 \%$ of Lab4 and $67 \%$ of hFMT mice developed either mild or moderate-to-severe disease. In contrast, only $43 \%$ of vancomycin-treated TSHRimmunized developed mostly mild GO (Fig. 5e).

\section{Microbiome modification changes profile of lymphocytes}

Flow cytometry analysis of orbital draining lymph node revealed that $\mathrm{CD}_{4}^{+}$lymphocyte numbers remained unaffected (Fig. 6a), whilst $\mathrm{CD} 4{ }^{+} \mathrm{CD} 25^{+}$(regulatory $\mathrm{T}$ cells; Tregs) numbers were significantly lowered in vancomycintreated TSHR- and Bgal-immunized mice (Fig. 6b) suggesting lower autoimmunity incidence and disease severity that we observed in this group is not necessarily regulated by local mechanisms. Lab4-treated $\beta$ gal mice showed significantly higher Tregs compared with the $\mathrm{ddH}_{2} \mathrm{O}$ and hFMT- $\beta$ gal groups. However, such an elevation in Tregs was not observed in Lab4-treated mice when they underwent induction of $\mathrm{GD} / \mathrm{GO}$ by receiving TSHR immunization. TSHR-ddH $\mathrm{H}_{2} \mathrm{O}$ mice showed positive correlations between $\mathrm{CD} 4{ }^{+} \mathrm{CD} 25^{+}$levels and Bacteroides and Alistipes genera and between 
Lachnospiraceae family. $\mathrm{CD}_{4}^{+}$levels negatively correlated with six genera, including Bacteroides and Parabacteroides spp. In the vancomycin-TSHR immunization group, Akkermansia spp. positively correlated with $\mathrm{CD} 4{ }^{+} \mathrm{CD} 25^{+}$levels, whilst an uncultured Bacteroidetes was positively correlated with $\mathrm{CD}^{+}{ }^{+} \mathrm{T}$ cells. In Lab4-TSHR, genus Akkermansia negatively correlated, whilst Alistipes spp. positively correlated with $\mathrm{CD} 4{ }^{+} \mathrm{CD} 25^{+}$levels. Uncultured Bacteroidetes correlated positively with $\mathrm{CD} 4{ }^{+} \mathrm{CD} 25$ and negatively with $\mathrm{CD} 4^{+}$. Uncultured Actinobacteria displayed a strong negative correlation to $\mathrm{CD}^{+}$, as for Bacteroides and Parabacteroides spp. In hFMT-TSHR, genera Bacteroides and Alistipes negatively correlated to $\mathrm{CD}^{+}$(Figure S6).

\section{Microbiome modification affects circulating cytokine and chemokine levels}

Chemokines and cytokines were measured in sera at sacrifice using a multiplex system. Several were below the limit of detection (IL-17/17A, IL-2 and IFN- $\gamma$ ), and no significant differences were seen in IL-10, CCL20, IL-6 or TNF-alpha. The chemokine CCL5/RANTES showed a trend to increase in TSHR-immunized compared with Bgal only in $\mathrm{ddH}_{2} \mathrm{O}$ treated mice $(P=0.37)$ whilst IL-4 was significantly higher in TSHR-dd $\mathrm{H}_{2} \mathrm{O}$-compared with Bgal $(P=0.0170)$ (Fig. 6c). Vancomycin treatment increased IL-4 levels significantly in $\beta$ gal mice compared to $\mathrm{ddH}_{2} \mathrm{O}$ treatment $(P=0.0286)$ and in $\beta$ galimmunized mice compared to hFMT-TSHR mice $(P=$ 0.0228) which correlated with Verrucomicrobia and Firmicutes. In TSHR-Lab4 IL-4 increased compared to hFMT $(P=0.0208)$ (Fig. 6d).

Significant positive correlations between CCL5 and two unidentified and uncultured Firmicutes were observed in TSHR- $\mathrm{ddH}_{2} \mathrm{O}$ mice. A positive correlation between IL-4 and Akkermansia spp., a negative correlation with Lachnoclostridium spp. Lab4-TSHR and a positive correlation between CCL5 and Parabacteroides spp. were reported in TSHR-vancomycin mice (Figure S6).

\section{Discussion}

The current study extends our previous work in which we demonstrated significant differences in microbiota composition from inbred BALB/c mice, undergoing the same immunization protocol, in specific pathogen-free (SPF) units in different locations. The results were obtained using a robust GD/GO mouse model and supported our hypothesis that the bacterial environment may contribute to determining TSHR-induced responses and hence influence the outcome and reproducibility of induced GD and GO.

For the first time, we investigated whether the gut microbiota is necessary for the induction of GD/GO, by modifying its composition from early-life and prior to the hTSHR immunization regimen. Modulation of the gut microbiome has been reported to improve or exacerbate other autoimmune diseases. We obtained striking results: antibiotic treatment had a profound impact on the gut microbiome which was associated with significantly reduced GD-like disease (pathogenic autoantibodies, elevated thyroxine, hyperthyroid thyroid morphology) and GO-like histopathology and cellular changes (orbital adipogenesis and muscle atrophy). In contrast, mice receiving hFMT from patients with severe GO, initially shared similarity of their gut microbiota composition with their donors, accompanied by increased severity of GD-like disease. The fact that muscle atrophy decreased but orbital BAT volume was increased in hFMT recipients suggests different pathogenetic mechanisms for these features of GO. Mice receiving probiotic treatment had significantly higher numbers of $\mathrm{CD} 25^{+}$Tregs in orbital draining lymph nodes.

Consistent with previous findings [43], the effects of long-term vancomycin treatment were dramatic and included depletion of the richness and diversity indices accompanied by reduction of Gram-positive bacteria (mainly Firmicutes phylum) and an increase in Proteobacteria species, including Salmonella spp., Pseudomonas spp. and E. coli. Vancomycin also fostered growth of resistant and/or compensating species, e.g. the highest counts of the genus Bacteroides, which correlated negatively with total orbital fat and genus Akkermansia which showed a significant negative correlation with brown and total fat, $\mathrm{CD} 4^{+}$and $\mathrm{CD} 8^{+}$in the orbit (data not shown) and a positive correlation with the $\mathrm{CD} 25^{+}$ (Tregs) in TSHR-immune mice. Akkermansia muciniphila constitutes a single-species of the genus Akkermansia [44], which is involved in mucin degradation [45]. The postnatal administration of vancomycin in non-obese diabetic (NOD) mice reduced the incidence of T1D along with the increased proportion of $\mathrm{A}$. muciniphila [46], although other studies showed exacerbation of T1D in murine models and human subjects in the presence of antibiotics [47, 48].

At the start of immunization, some hFMT mice had a GO-like environment in their gut. In particular, mice showing the highest engraftment were housed in the same cage, suggesting a possible cage effect. However, we repeated the analysis removing the "highly-colonized" mice and similar results were confirmed (Figure S4). At the midpoint (after 6 weeks of washout), no similarity between hFMT-receiving mice and GO donors was observed, whilst at the end of the experiment, the large intestines of both $\mathrm{ddH}_{2} \mathrm{O}$ and hFMT mice shared the same similarity with human samples. The algorithm used OTUs at the family level, which may lack host 
specificity, since no similarity was observed between mice and humans at lower taxonomies. The definition of FMT success is primarily based on a positive clinical response in the recipient. However, from a microbiological perspective, FMT success can also be defined by a shift in the gut microbiome profile of an individual towards that of the donor. We argue that a successful engraftment may be a two-step process; first requiring the transplanted microbiome to engraft within the new host and augment the local commensal community, after which clinical response may be observed.

The washout period may have reduced the transferred bacteria, and the lack of prior treatment, such as bowel cleansing or antibiotic treatment of dams, despite pups being gavaged from birth, may have allowed some transmission of maternal gut microbiota, which can induce colonization resistance [49]. Of note, freeze-dried FMT proved to be a safe and efficient treatment of diarrheal episodes in recurrent Clostridioides difficile infections, often accompanied by an increased/restored microbiota diversity and a successful engraftment [50-52]. In mice, after bowel cleansing, the engraftment of a single FMT gavage lasted up to 4 weeks, whilst repeated gavages (i.e. twice a week for 4 weeks) negatively impacted the stability of the gut microbiota [53]. Furthermore we used fecal material from people with severe GO, our parallel studies in patients with GD and/or GO reveal that most significant differences in gut microbiota appeared in mild GO, compared with GD or healthy controls. Bacterial abundance and diversity of patients with severe GO more closely resembled that of healthy controls, possibly due to the extensive treatments, including corticosteroids, experienced by this group.

Probiotic supplements are associated with health benefits in humans, including immune-modulation of the recipient [54], and this was demonstrated in our Lab4treated mice. Specifically, CD $4^{+} \mathrm{CD} 25^{+}$Tregs were induced in the $\beta$ gal, but not in the TSHR-immune group, although the latter showed interesting correlations, e.g. Bacteroidetes-uncultured genera, Bacteroides and Alistipes negatively correlated with $\mathrm{CD}^{+}$and simultaneously positively with $\mathrm{CD} 4^{+} \mathrm{CD} 25^{+}$Tregs. This suggests that although probiotic treatment increases local Tregs, this is unable to prevent breakdown in tolerance following TSHR immunization.

The significantly lower $\mathrm{CD} 4^{+} \mathrm{CD} 25^{+}$Tregs numbers in vancomycin-treated mice in our study are in line with previous findings. Vancomycin selectively targets grampositive bacteria which produce the short-chain fatty acid butyrate [55]. Butyrate promotes the differentiation of Tregs from naive $\mathrm{CD}_{4}^{+} \mathrm{T}$ cells and is known for its anti-inflammatory effects [56].

Beneficial effects conferred by probiotics are not always related to the effective colonization of the host mucosa by probiotic species and also occur transiently [57]. Therefore, it was not surprising that no increase of Lactobacillus sp. was observed in Lab4-treated LGI microbiota. However, Bifidobacterium sp. was not detected at all from the gut microbiota of our BALB/C mice (even before the removal of low abundant OTUs), as previously reported $[25,27,28]$, possibly due to environmental factors (e.g. animal housing) or because of a poor colonizer setting.

Lab4-treated TSHR-immune mice showed significantly higher T4 levels and orbital brown fat compared to Bgal. Varian and collaborators treated aging outbred mice daily with Lactobacillus reuteri and reported increased T4 levels, accompanied by weight loss and increased activity compared to untreated. Authors also observed an enlarged thyroid and induced activity dependent upon $\mathrm{CD} 4{ }^{+} \mathrm{CD} 25^{+}$Tregs [58]. Administration of L. acidophilus for 32 days increased TSH and T3 levels but not T4 in weaning rats [59]. Whilst providing a "healthful aging" in 1-year-old mice [58], it is possible that probiotics worsen hyperthyroidism following TSHR immunization. On the contrary, supplementation of Bifidobacterium lactis and Lactobacillus rhamnosus mitigated disease outcome in experimental autoimmune thyroiditis (similar to Hashimoto's thyroiditis) [11]. In Hashimoto's thyroiditis patients, administration of probiotics stabilized hormonal fluctuations during therapy, although no significant protective effects were observed in hyperthyroid humans compared to healthy controls [60]. In other autoimmune conditions, prevention of T1D onset was observed in NOD mice receiving multiple strains of Lactobacillus and Bifidobacterium spp. and of Streptococcus salivarius subsp. thermophilus which was associated with increased production of anti-inflammatory IL10 [61]. Similarly, administration of probiotics reversed the EAE model phenotype with an upregulation of Tregs via IL-10 production [62].

The study also shows some limitations. As mentioned above, hFMT was not accompanied by any pretreatment. Usage of freeze-dried material would have probably been more effective if we obtained samples from mild GO rather than sight-threatening disease, particularly since patients had gone through massive interventions before donating fecal samples. If and how each of those treatment regimens has influenced patients' gut microbiota is not completely clear. Moreover, despite administering a probiotic containing two bifidobacteria species, we were unable to detect them in any of the mice studied, for the reasons already mentioned.

The fact that TSHR-immunized mice gained weight was a surprise and contrasts with GD patients who lose weight during the active stage of disease, although most gain weight when TRAb-positive and euthyroid [63]. However, other than in patients, female mice were 
shown to gain weight in hyperthyroidism induced by $\mathrm{T} 4$ treatment, most likely due to higher food intake [64]. Likewise, in a recent study, we showed that hyperthyroid TSHR immune mice gain weight [42]. Consistently, in the current study, we found that weight gain correlated positively with T4 values or with TSAb in the TSHR immune mice but not in the $\beta$ gal- $\mathrm{dd}_{2} \mathrm{O}$ mice (Figure S9). Of note, hFMT mice showed the most significant weight gain suggesting a strong hyperthyroid hormone state during the experimental course. Indeed, hFMT mice showed the strongest elevated hyperactive thyroid morphology confirming this assumption. Induction of hyperthyroidism was highly variable in the mice, whether assessed by T4 measurement or thyroid morphology. The heterogeneity of autoimmune thyroid dysfunction in the model reflects the situation in patients $[26,35]$. Most GO patients had developed hyperthyroidism when GO is diagnosed but some GO patients developed GO although euthyroid or even hypothyroid [65]. Whether and to what extent the thyroid hormone level directly impacts/modulates the outcome of GO in the model is unclear and needs to be addressed in further studies.

Our findings are relevant to human disease, as illustrated by the similar perturbations of the gut microbiota (increased Firmicutes and decreased Bacteroidetes) we have found in TSHR-immunized mice and GD/GO patients ( $\mathrm{ms}$ in preparation). Furthermore, long-term vancomycin treatment resulted in a reduced and resilient microbiota, which included high counts of Bacteroides spp. (the opposite of that found in murine and human GD/GO) and Akkermansia spp. Such an antibioticmodified-gut microbiota reduced incidence and severity of disease induced by subsequent TSHR immunization. In contrast, hFMT exacerbated GD-like pathology, i.e. the disease phenotype had been partially transferred, and was associated with the lowest Bacteroidetes counts of all four TSHR-immunized groups. Whether increased Firmicutes or decreased Bacteroidetes has more effect on pathogenesis is not clear; some disease states have been associated with gain of function perturbation of the gut microbiota, e.g. colorectal cancer and Parkinson's disease whereas others have been associated with loss of function imbalance, e.g. inflammatory bowel disease. Of note, in most chronic conditions, decreased microbiota diversity is a common theme [66].

The lack of induced disease in the vancomycin-treated TSHR-immune mice confirms that the gut microbiota is necessary for GD/GO to be successfully induced, potentially training the immune system at the early stage of life. Ivanov and collaborators reported a decreased Th17-produced proinflammatory cytokines milieu in the small intestines of the EAE newborn pups treated with vancomycin, which may have contributed in the protection from the disease development [67]. A very recent paper by $\mathrm{Su}$ et al. reported significantly reduced SCFA-producing bacteria in GD patients. Furthermore, propionic acid from Bacteroides spp increased Tregs whilst reducing Th17 cells [68]. This ties in with studies from Fang and colleagues who identified a significantly higher proportion of IL-17A-producing $\mathrm{T}$ cells in GO patients and which correlated with orbital fibrotic change [69]. In our experiments, circulating IL-17/17A, IL-2 and IFN- $\gamma$ levels were below the limit of detection, although cytokine measurements were possible only at the end of the experiment. In a few TSHR-immunized mice, elevated levels of IL-10, IL-6, CCL-20 and TNFalpha were observed (data not shown). However, we did observe a trend towards increased CCL5/RANTES levels in TSHR-immunized mice, a chemokine which is released by orbital fibroblasts leading to $\mathrm{T}$ cell migration and inflammatory responses [70]. IL-4, a cytokine produced by Th2 cells which is increased in serum of patients with GD [71] and which has mitogen effects on fibroblasts [72], was found to be increased in TSHR$\mathrm{ddH}_{2} \mathrm{O}$ mice and in Bgal mice after treatment with Lab4 or vancomycin. We did not confirm the reported reduction of IL-4 by treatment with probiotics [73] although our findings agree with Sun and colleagues who showed upregulation of IL-4 gene expression after vancomycin treatment. Alternatively, since the TSHR-induced model does not employ conventional adjuvants, given its close interplay with the immune system, the gut microbiota can itself act as a natural adjuvant, promoting (or not) the second immune stimulus needed for the activation of the autoimmune response, as reported by Oh and co-workers [74].

We speculate that the Lab4 administration promoted an anti-inflammatory response, increasing the Tregs in the $\beta$ gal- $\mathrm{ddH}_{2} \mathrm{O}$ mice, which was neutralized by the TSHR immunization, despite gut microbiota-correlating features. Also, the lack of induced disease in vancomycin-treated mice was accompanied by the lack of Tregs in both $\beta \mathrm{gal}$ and TSHR mice. Future studies in which immune cells are transferred from probiotictreated mice to naive recipients, prior to TSHR immunization, will facilitate identification of the $\mathrm{T}$ cell subsets implicated in GD/GO.

\section{Conclusions}

In conclusion, our results strongly support a pivotal role for the gut microbiota in TSHR-induced disease (Suppl. Figure S10). Whilst changes to the gut microbiota have a profound effect on quantifiable GD endocrine and immune factors, the impact on GO cellular changes is more nuanced. Future studies will address the translational potential of our work, including clinical trials of appropriate antibiotics, which are warranted to improve 
outcomes for patients with GD/GO. Also, a placebocontrolled randomized trial with probiotics has been conducted in patients to investigate the potential protective effect on hormonal fluctuations on GD/GO during anti-thyroid treatments.

\section{Supplementary Information}

The online version contains supplementary material available at https://doi. org/10.1186/s40168-020-00952-4

Additional file 1: Supplementary methods. Table S1. Characteristics of patients with sight-threatening GO recruited at the University Hospital Duisburg-Essen providing samples for hFMT production.

Additional file 2: Figure S1. Supplementary results for the endpoint gut microbiota analysis. (A and B) Microbiota composition according to different anatomical samples in TSHR and $\beta$ gal-immunized mice (samples/source: colon $=48$, entire $=30$, small $=51$ from final timepoint and stool $=105$ from baseline and mid-timepoint). (A) Alpha-diversity indices of the source of the microbiota sampled, Wilcoxon-Mann BH corrected test: ${ }^{* *} P<0.05$. (B) NMDS of Bray-Curtis distances according to immunizations and sources at the endpoint. PERMANOVA between entire-colon samples $P>0.05$. ( $C$ and D) Endpoint composition of the LGI microbiota amongst treatments in $\beta$ gal-immunized mice. (n ßgal mice/treatment at endpoint: control =8, hFMT =8, Lab4 = 10, vancomycin = 19). (C) Alpha diversity amongst treatments, Wilcoxon-Mann $\mathrm{BH}$ corrected test:***P < 0.001. ( $D$ to $G$ ) RandomForest of a model excluding vancomycin samples ( $\mathrm{n}$ mice/treatment endpoint: control $=20, \mathrm{hFMT}=19$, Lab4 $=20$ ). (D) Confusion matrix for treatments w/o vancomycin samples. Diagonal boxes represent the number of samples correctly predicted. (E) Top-10 variables of treatment classification according to the Mean Decrease Gini, including the microbiota source as an effect related to figure E. (F) Confusion matrix for immunizations in a model w/o vancomycin samples. ( $n$ mice/immunization endpoint: TSHR $=33$ and $\beta g a l=26$ ). (G) Top-10 variables of immunizations classification according to the Mean Decrease Gini, including the microbiota source and treatments as an effect related to figure G. Wilcoxon-Mann test with $\mathrm{BH}$ correction: ${ }^{* *} \mathrm{P}<0.005$; ${ }^{* *} \mathrm{P}<$ $0.01 ;{ }^{*} P<0.05$

Additional file 3: Figure S2. Heatmap of the differentially abundant genera amongst treatments in TSHR-immunized mice. Median abundances were scaled according to row Z-score. Only genera with $P<0.5$ are represented

Additional file 4: Figure S3. Heatmap of the differentially abundant genera amongst treatments in $\beta$ gal mice. Median abundances were scaled according to row Z-score. Only genera with $P<0.5$ are represented.

Additional file 5: Figure S4. Composition of the fecal microbiota in GO patients donating the samples for the hFMT $(n=6)$ and healthy controls from the same region $(n=12)$. (A) Chaol alpha-diversity index. WilcoxonMann test, $P=0.80$. (B) Firmicutes to Bacteroidetes ratio. Wilcoxon-Mann test, $P=0.60$. (C) Heatmap of the top-50 most abundant genera in GO patients and healthy controls. Each column represents a sample. Relative abundances were scaled according to the row Z-score. (D) Viable composition of the fecal microbiota and of the freeze-dried powder used for hFMT evaluated through a standard microbiology cultivation approach. Missing bar-charts refer to a microorganism below the detection limit. (EPS $625 \mathrm{~kb}$ )

Additional file 6: Figure S5. Supplementary results for the time-series analysis. (A) Chao1 alpha-diversity indices at baseline, Wilcoxon-Mann test with $\mathrm{BH}$ correction: ${ }^{* * *} P<0.001$. ( $\mathrm{n}$ mice/treatment at baseline: control $=$ 20, hFMT $=19$, Lab4 = 20, vancomycin $=19$ ). (B) Heatmap of the differentially abundant genera amongst treatments at baseline. Median abundances were scaled according to the row Z-score. Only genera with $P<$ 0.05 are represented. (C) Alpha-diversity indices between timepoints in each treatment group ( $\mathrm{n}$ mice per treatment/timepoint: control baseline $=16$, $\mathrm{mid}=20 ;$ hFMT baseline $=15$, mid $=24$; Lab4 baseline $=14$, mid $=$ 22 ; vancomycin baseline $=20$, $\mathrm{mid}=28$ ), irrespective of the immunizations. Wilcoxon-Mann test with $\mathrm{BH}$ correction: ${ }^{* *} P<0.005$; ${ }^{* *} P$ $<0.01 ;{ }^{*} P<0.05$

Additional file 7: Figure S6. Correlation analysis between bacterial biomarkers and disease features. Pearson's correlation coefficient ( $r$ ) was used to test the correlations between bacterial biomarkers associated to both treatments and immunizations (from Fig. 1e and g) in (A) ddH2O, (B) vancomycin, (C) Lab4 and (D) hFMT treatment group at the final timepoint. Only TSHR immunization is shown. Only correlations with $\mathrm{P}<$ 0.05 are shown and the strength of the correlation is represented by the change in color from blue (negative) to red (positive correlation). (EPS $262 \mathrm{~kb})$

Additional file 8: Figure S7. Mice eye signs and orbital tissues abnormalities analysed histologically. (A) Mice eye signs indicating orbital disease. Representative images of a ßgal mouse lacking pathological eye signs and of a TSHR-immunized mouse with acute signs of inflammation and/or proptosis. (B) UCP-1 (uncoupling protein -1) as a marker for brown fat tissue (BAT). Elevated portions of small vacuoled BAT were present in TSHR-immunized mice. Representative pictures of stainings are shown. (C, D) CD3 as a marker for T cells. Some $\mathrm{CD}^{+} \mathrm{T}$ cells (indicated by arrows) were detected in adipose tissues (C) and in muscle tissues (D) of $\mathrm{Bgal}$ and TSHR-immunized mice. Immunohistochemistry of orbital tissues was carried out as described in detail before [40]

Additional file 9: Figure S8. Caging effects during the hFMT engraftment did not impact the induced phenotype. (A) Non-metric dimensional scaling (NMDS) based on Bray-Curtis distances according to cages, specifically for the hFMT-receiving mouse group in each of the timepoints sampled. Baseline and mid-timepoint used fecal samples, whilst the final timepoint was on LGI microbiota. (B) Firmicutes to Bacteroidetes ratio in each hFMT-cage and in each timepoint. Pairwise Wilcoxon-Mann test: ${ }^{* *} P<0.05$; ${ }^{* * *} P<0.001$, ns $P>0.05$. (C and D) Reanalysis without the samples from cage 8 , as considered to be "high-colonized mice". (C) Bacteroides spp. relative abundances between immunizations and in each timepoint. Wilcoxon-Mann test: ns $P>0.05,{ }^{* *} P<$ 0.01. (D) Random Forest confusion matrix of the classification for treatments (all immunizations together) using the endpoint LGl genus-level microbiota, as in Fig. 1e but without samples from cage 8. Diagonal boxes represent the number of samples correctly predicted. (n mice/ group endpoint: control $=20$, hFMT $=15$, Lab4 = 20, vancomycin = 19). ( $E$ and F) Evaluation of the autoimmune hyperthyroidism (E) and the GO (F) Z-score with specific regard to the cage 8 samples. No significant differences were observed between other samples. (EPS 272 kb)

Additional file 10: Figure S9. Correlation between weight gain and clinical features. Pearson's correlation coefficient ( $r$ ) was used to test the correlations between weight and T4 (A) and TSAb (B). (EPS 11601 kb)

Additional file 11: Table S2. Number of positive mice for each disease parameter. Numbers of TSHR-immunized mice positive for thyroidstimulating antibodies (TSAbs), increased circulating thyroxine (T4), hyperplastic thyroid morphology, orbital brown fat (BAT) enlargement or muscle fiber atrophy are reported. The threshold for positivity was defined as upper $99 \% \mathrm{Cl}$ of the corresponding $\beta$ gal groups. Table S3. Classification of total outcome of autoimmune hyperthyroidism and orbitopathy. Disease classification was done along the Z-Score values in Figure 8 . The number of mice is given in \%. Subclinical disease (Z-Score $<0)$ : these mice displayed no overt signs of autoimmune hyperthyroidism or orbitopathy although they developed TSHR antibodies. Clinical disease (Z-Score $>0$ ): These mice displayed clear signs of autoimmune hyperthyroidism and/or orbital pathology. Clinical disease is classified in mild and moderate/severe in accordance with the $Z$ Score values as indicated (mild: Z Score 01; moderate/severe: Z-Score >1).

Additional file 12: Figure S10. Schematic model. Modulation of the gut microbiota in a mouse model of Graves' orbitopathy has an impact on induced disease. Female BALB/C mice were immunized with TSHR-A subunit and their intestinal microbiota were depleted with antibiotics (vancomycin) or skewed with probiotics (Lab4) and human fecal material transfer (hFMT) from severely affected patients with known increased Firmicutes/Bacteroidetes ratio, in order to study the effects of the microbiome on induced Graves' Disease (GD)/ Graves' orbitopathy (GO). Incidence and severity of GD (TSHR autoantibodies, thyroid histology, 
thyroxine level) and GO (orbital fat and muscle histology), lymphocyte phenotype, cytokine profile and gut microbiota were analysed at sacrifice ( 22 weeks). The results show that, whilst microbiome manipulation with all treatments specifically alter microbiome composition, hFMT increased severity of GD-like disease but treatment with Lab4 exacerbated induced autoimmune hyperthyroidism and GO. Vancomycin led to a significant increase of the genus Bacteroides and less pronounced GD- and GO-like changes.

\section{Abbreviations}

ATD: Autoimmune thyroid disease; BAT: Brown adipose tissue; BH: BenjaminiHochberg; CD: Cluster of differentiation; CHO: Chinese hamster ovary cells; CSS: Cumulative sum scaling; $\mathrm{ddH}_{2} \mathrm{O}$ : Deionized water; EAE: Experimental autoimmune encephalomyelitis; EAT: Experimental autoimmune thyroiditis; GALT: Gut-associated lymphoid tissue; GD: Graves' disease; GO: Graves' orbitopathy; hFMT: Humanized fecal material transplant: LGI: Lower gastrointestinal tract; MRD: Maximum recovery diluent; MRS: Man, Rogosa and Sharpe broth; MS: Multiple sclerosis; NMDS: Non-metric dimensional scaling; NOD: Non-obese diabetic; OTU: Operational taxonomic unit; PERM ANOVA: Permutational analysis of variance; QIIME: Quantitative insights into microbial ecology; RF: Random forest; rRNA: Ribosomal RNA; S: Svedberg; SPF: Specific pathogen free; spp: Subspecies; T1D: Type-1 diabetes; T3: Triiodothyronine; T4: Thyroxine; Th: T helper cells; TRAb: Total TSHR antibodies; Tregs: Regulatory T cells; TSAbs: Thyroid-stimulating antibodies; TSH: Thyroid-stimulating hormone; TSHR: Thyroid-stimulating hormone receptor; ßgal: Beta-galactosidase

\section{Acknowledgements}

We acknowledge the work of the other members of the INDIGO consortium: Lei Zhang, Mario Salvi, Iveta Garaiova and Giuseppe Colucci, and of the patients for donating their fecal samples used in this study. INDIGO Consortium: http://www.indigo-iapp.eu

\section{Authors' contributions}

SM and UBP conducted the animal experiments, including disease phenotyping and analysis, assisted by HLV who also prepared the hFMT. GM performed all microbiome analyses, guided by FB and JRM. DC, DM and SP contributed to the study design and production of hFMT and Lab4. MH, AD, AW, CJ and SP contributed to the animal experiments. AE provided access to patients and clinical evaluation of the animal model. ML designed and managed the project and coordinated the analyses and manuscript preparation. All the authors contributed to the drafting and critical review of the manuscript. SM, HLV and GM share first authorship. AE, ML and UBP share corresponding authorship. The authors read and approved the final manuscript.

\section{Funding}

This work was supported by Marie-Sklodowska Curie Industry IndustryAcademia Pathways and Partnerships (IAPP) action, GA number 612116 project INDIGO

\section{Availability of data and materials}

165 rRNA gene sequencing reads generated in this work were submitted under the NCBI accession ID PRJNA635258.

\section{Ethics approval and consent to participate}

The animal study was approved by the North Rhine Westphalian State Agency for Nature, Environment and Consumer Protection, Germany. The use of fecal material from patients with sight-threatening GO was approved by the ethical commission of the medical faculty of the University Duisburg-Essen, Germany, and written informed consent was obtained from each patient at the time of the enrolment.

\section{Consent for publication}

Not applicable

\section{Competing interests}

HLV, DC, SP and DM are/were employees of Cultech Ltd. JRM and GM are involved in other collaborative projects with Cultech Ltd. The other authors declare that they have no competing interests.

\section{Author details}

'Molecular Ophthalmology, Department of Ophthalmology, University Hospital Essen, University of Duisburg-Essen, 45147 Essen, Germany. ${ }^{2}$ Current address: Latner Thoracic Surgery Laboratories, Toronto General Research Institute, University Health Network and University of Toronto, Toronto, Canada. ${ }^{3}$ Institute of Medical Microbiology, University Hospital Essen, University of Duisburg-Essen, Essen, Germany. ${ }^{4}$ Cultech Ltd., Baglan, Port Talbot, UK. ${ }^{5}$ Division of Infection \& Immunity, School of Medicine, Cardiff University, UHW main building, Heath Park, Cardiff CF14 4XW, UK. ${ }^{6}$ Department of Bioinformatics, PTP Science Park Srl, Lodi, Italy. ${ }^{7}$ Current address: Computational metagenomics, Department $\mathrm{ClBIO}$, University of Trento, Trento, Italy. ${ }^{8}$ Graves' Orbitopathy Center, Endocrinology, Department of Clinical Sciences and Community Health, Fondazione Ca'Granda IRCCS, University of Milan, Milan, Italy. ${ }^{9}$ Italian National Research Council (CNR), Milano, Italy. ${ }^{10}$ Department of Ophthalmology, University Hospital Essen, University of Duisburg-Essen, 45147 Essen, Germany. ${ }^{11}$ Department of Histopathology, King's College Hospital, King's College, London, UK. ${ }^{12}$ School of Biosciences, Cardiff University, Cardiff, UK. ${ }^{13}$ Department of Metabolism, Digestion and Reproduction, Imperial College London, London, UK.

\section{Received: 5 November 2020 Accepted: 6 December 2020} Published online: 16 February 2021

\section{References}

1. Maslowski KM, Vieira AT, Ng A, Kranich J, Sierro F, Yu D, et al. Regulation of inflammatory responses by gut microbiota and chemoattractant receptor GPR43. Nature. 2009:461:1282-6.

2. Lo Presti A, Zorzi F, Del Chierico F, Altomare A, Cocca S, Avola A, et al. Fecal and mucosal microbiota profiling in irritable bowel syndrome and inflammatory bowel disease. Front Microbiol. 2019;10:1655.

3. Chen J, Chia N, Kalari KR, Yao JZ, Novotna M, Paz Soldan MM, et al. Multiple sclerosis patients have a distinct gut microbiota compared to healthy controls. Sci Rep. 2016;6:28484.

4. Nagao-Kitamoto H, Shreiner AB, Gillilland MG, Kitamoto S, Ishii C, Hirayama A, et al. Functional characterization of inflammatory bowel disease-associated gut dysbiosis in gnotobiotic mice [Internet]. Cell Mol Gastroenterol Hepatol. 2016:468-81. https://doi.org/10.1016/j.jcmgh.2016.02.003.

5. Pan H, Guo R, Ju Y, Wang Q, Zhu J, Xie Y, et al. A single bacterium restores the microbiome dysbiosis to protect bones from destruction in a rat model of rheumatoid arthritis. Microbiome. 2019;7:107.

6. Vatanen T, Franzosa EA, Schwager R, Tripathi S, Arthur TD, Vehik K, et al. The human gut microbiome in early-onset type 1 diabetes from the TEDDY study. Nature. 2018;562:589-94.

7. Zhang X, Zhang D, Jia H, Feng Q, Wang D, Liang D, et al. The oral and gut microbiomes are perturbed in rheumatoid arthritis and partly normalized after treatment. Nat Med. 2015;21:895-905.

8. Mu Q, Tavella VJ, Kirby JL, Cecere TE, Chung M, Lee J, et al. Antibiotics ameliorate lupus-like symptoms in mice [Internet]. Scientific Rep. 2017. https://doi.org/10.1038/s41598-017-14223-0.

9. Berer K, Gerdes LA, Cekanaviciute E, Jia X, Xiao L, Xia Z, et al. Gut microbiota from multiple sclerosis patients enables spontaneous autoimmune encephalomyelitis in mice. Proc Natl Acad Sci U S A. 2017; 114:10719-24.

10. Takata K, Kinoshita M, Okuno T, Moriya M, Kohda T, Honorat JA, et al. The lactic acid bacterium Pediococcus acidilactici suppresses autoimmune encephalomyelitis by inducing IL-10-producing regulatory T cells. PLoS One. 2011;6:e27644

11. Zhou JS, Gill HS. Immunostimulatory probiotic Lactobacillus rhamnosus HNO01 and Bifidobacterium lactis HN019 do not induce pathological inflammation in mouse model of experimental autoimmune thyroiditis. Int $J$ Food Microbiol. 2005;103:97-104

12. Bahn RS. Pathophysiology of Graves' ophthalmopathy: the cycle of disease. J Clin Endocrinol Metab. 2003; Available from: https://academic.oup.com/ jcem/article-abstract/88/5/1939/2845094. academic.oup.com.

13. Ishaq HM, Mohammad IS, Shahzad M, Ma C, Raza MA, Wu X, et al. Molecular alteration analysis of human gut microbial composition in Graves' disease patients. Int J Biol Sci. 2018;14:1558-70.

14. Shi T-T, Xin Z, Hua L, Zhao R-X, Yang Y-L, Wang H, et al. Alterations in the intestinal microbiota of patients with severe and active Graves' orbitopathy: a cross-sectional study. J Endocrinol Invest. 2019;42:967-78. 
15. Perros $P$, Hegedüs $L$, Bartalena L, Marcocci C, Kahaly GJ, Baldeschi L, et al. Graves' orbitopathy as a rare disease in Europe: a European Group on Graves' Orbitopathy (EUGOGO) position statement [Internet]. Orphanet J Rare Dis. 2017. https://doi.org/10.1186/s13023-017-0625-1.

16. Wiersinga WM. Advances in treatment of active, moderate-to-severe Graves' ophthalmopathy. Lancet Diabetes Endocrinol. 2017;5:134-42.

17. Taylor PN, Zhang L, Lee RWJ, Muller I, Ezra DG, Dayan CM, et al. New insights into the pathogenesis and nonsurgical management of Graves orbitopathy. Nat Rev Endocrinol. 2020;16:104-16.

18. Weetman AP. Immunity, thyroid function and pregnancy: molecular mechanisms. Nat Rev Endocrinol. 2010;6:311-8.

19. Wiesweg B, Johnson KTM, Eckstein AK, Berchner-Pfannschmidt U. Current insights into animal models of Graves' disease and orbitopathy. Horm Metab Res. 2013:45:549-55.

20. Bagnasco M, Bossert I, Pesce G. Stress and autoimmune thyroid diseases. Neuroimmunomodulation. 2006;13:309-17.

21. Eckstein A, Quadbeck B, Mueller G, Rettenmeier AW, Hoermann R, Mann K, et al. Impact of smoking on the response to treatment of thyroid associated ophthalmopathy. Br J Ophthalmol. 2003;87:773-6.

22. Marinò M, Latrofa F, Menconi F, Chiovato L, Vitti P. Role of genetic and nongenetic factors in the etiology of Graves' disease. J Endocrinol Invest. 2015; 38:283-94.

23. Köhling $\mathrm{HL}$, Plummer SF, Marchesi JR, Davidge KS, Ludgate M. The microbiota and autoimmunity: their role in thyroid autoimmune diseases. Clin Immunol. 2017:183:63-74.

24. Covelli D, Ludgate M. The thyroid, the eyes and the gut: a possible connection. J Endocrinol Invest. 2017:40:567-76.

25. Masetti G, Moshkelgosha S, Köhling H-L, Covelli D, Banga JP, BerchnerPfannschmidt $U$, et al. Gut microbiota in experimental murine model of Graves' orbitopathy established in different environments may modulate clinical presentation of disease. Microbiome. 2018;6:97.

26. Moshkelgosha S, So P-W, Deasy N, Diaz-Cano S, Paul Banga J. Cutting edge: retrobulbar inflammation, adipogenesis, and acute orbital congestion in a preclinical female mouse model of Graves' orbitopathy induced by thyrotropin receptor plasmid-in vivo electroporation [Internet]. Endocrinology. 2013:3008-15. https://doi.org/10.1210/en.2013-1576.

27. Berchner-Pfannschmidt U, Moshkelgosha S, Diaz-Cano S, Edelmann B, Görtz G-E, Horstmann $\mathrm{M}$, et al. Comparative assessment of female mouse model of Graves orbitopathy under different environments, accompanied by proinflammatory cytokine and T-cell responses to thyrotropin hormone receptor antigen [Internet]. Endocrinology. 2016:1673-82. https:/doi.org/10.1210/en.2015-1829.

28. Moshkelgosha S, Masetti G, Berchner-Pfannschmidt U, Verhasselt HL, Horstmann M, Diaz-Cano S, et al. Gut microbiome in BALB/C and C57BL/6J mice undergoing experimental thyroid autoimmunity associate with differences in immunological responses and thyroid function. Horm Metab Res. 2018;50:932-41.

29. Chen C-R, MCLachlan SM, Rapoport B. Thyrotropin (TSH) receptor residue E251 in the extracellular leucine-rich repeat domain is critical for linking TSH binding to receptor activation [Internet]. Endocrinology. 2010:1940-7. https://doi.org/10.1210/en.2009-1430.

30. Schott M. Vitamin D deficiency modulates Graves' hyperthyroidism induced in BALB/c mice by thyrotropin receptor immunization [Internet]. Yearbook of. Endocrinology. 2009:97-8. https://doi.org/10. 1016/s0084-3741(09)79323-0.

31. Bartalena L, Baldeschi L, Boboridis K, Eckstein A, Kahaly GJ, Marcocci C, et al. The 2016 European Thyroid Association/European Group on Graves orbitopathy guidelines for the management of Graves' Orbitopathy [Internet]. Eur Thyroid J. 2016:9-26. https://doi.org/10.1159/000443828.

32. Caporaso JG, Kuczynski J, Stombaugh J, Bittinger K, Bushman FD, Costello EK, et al. QIIME allows analysis of high-throughput community sequencing data. Nat Methods. 2010;7:335-6.

33. Quast C, Pruesse E, Yilmaz P, Gerken J, Schweer T, Yarza P, et al. The SILVA ribosomal RNA gene database project: improved data processing and webbased tools. Nucleic Acids Res. 2013:41:D590-6.

34. Paulson JN, Stine OC, Bravo HC, Pop M. Differential abundance analysis for microbial marker-gene surveys. Nat Methods. 2013;10:1200-2.

35. Schlüter A, Eckstein AK, Brenzel A, Horstmann M, Lang S, BerchnerPfannschmidt U, et al. Noninflammatory diffuse follicular hypertrophy/ hyperplasia of Graves disease: morphometric evaluation in an experimental mouse model [Internet]. European Thyroid Journal. 2018:111-9. https://doi. org/10.1159/000488079.
36. Box GEP, Cox DR. An analysis of transformations. J R Stat Soc. 1964; Available from: https:/rss.onlinelibrary.wiley.com/doi/abs/10.1111/j.2517-6161.1964.tb00553.x.

37. Anderson MJ. A new method for non-parametric multivariate analysis of variance [Internet]. Austral Ecol. 2001:32-46. https://doi.org/10.1111/j.14429993.2001.01070.pp.x.

38. Staley C, Kelly CR, Brandt L, Khoruts A, Sadowsky MJ. Complete microbiota engraftment is not essential for recovery from recurrent Clostridium difficile infection following fecal microbiota transplantation [Internet]. mBio. 2016. https://doi.org/10.1128/mbio.01965-16.

39. Knights D, Kuczynski J, Charlson ES, Zaneveld J, Mozer MC, Collman RG, et al. Bayesian community-wide culture-independent microbial source tracking. Nat Methods. 2011;8:761-3.

40. Johnson KTM, Wiesweg B, Schott M, Ehlers M, Müller M, Minich WB, et al. Examination of orbital tissues in murine models of Graves' disease reveals expression of UCP-1 and the TSHR in retrobulbar adipose tissues. Horm Metab Res. 2013;45:401-7.

41. Schlüter A, Flögel U, Diaz-Cano S, Görtz G-E, Stähr K, Oeverhaus M, et al. Graves' orbitopathy occurs sex-independently in an autoimmune hyperthyroid mouse model. Sci Rep. 2018;8:13096.

42. Plöhn S, Hose M, Schlüter A, Michel L, Diaz-Cano S, Hendgen-Cotta UB, et al. Fingolimod improves the outcome of experimental Graves' disease and associated orbitopathy by modulating the autoimmune response to the thyroid-stimulating hormone receptor. Thyroid. 2019;29:1286-301.

43. Sun L, Zhang $X$, Zhang $Y$, Zheng $K$, Xiang Q, Chen N, et al. Antibioticinduced disruption of gut microbiota alters local metabolomes and immune responses. Front Cell Infect Microbiol. 2019;9:99.

44. Derrien M, Collado MC, Ben-Amor K, Salminen S, de Vos WM. The mucin degrader Akkermansia muciniphila is an abundant resident of the human intestinal tract [Internet]. Appl Environ Microbiol. 2008:1646-8. https://doi. org/10.1128/aem.01226-07.

45. Derrien M, Van Baarlen P, Hooiveld G, Norin E, Müller M, de Vos WM. Modulation of mucosal immune response, tolerance, and proliferation in mice colonized by the mucin-degrader Akkermansia muciniphila. Front Microbiol. 2011;2:166.

46. Hansen CHF, Krych L, Nielsen DS, Vogensen FK, Hansen LH, Sørensen SJ, et al. Early life treatment with vancomycin propagates Akkermansia muciniphila and reduces diabetes incidence in the NOD mouse [Internet] Diabetologia. 2012:2285-94. https://doi.org/10.1007/s00125-012-2564-7.

47. Livanos AE, Greiner TU, Vangay P, Pathmasiri W, Stewart D, McRitchie S, et al. Antibiotic-mediated gut microbiome perturbation accelerates development of type 1 diabetes in mice [Internet]. Nat Microbiol. 2016. https://doi.org/10.1038/nmicrobiol.2016.140.

48. Candon S, Perez-Arroyo A, Marquet C, Valette F, Foray A-P, Pelletier B, et al. Antibiotics in early life alter the gut microbiome and increase disease incidence in a spontaneous mouse model of autoimmune insulin-dependent diabetes [Internet]. PLOS ONE. 2015:e0125448. https://doi.org/10.1371/journal.pone.0125448.

49. Ericsson AC, Franklin CL. Manipulating the gut microbiota: methods and challenges. ILAR J. 2015;56:205-17.

50. Hamilton MJ, Weingarden AR, Unno T, Khoruts A, Sadowsky MJ. Highthroughput DNA sequence analysis reveals stable engraftment of gut microbiota following transplantation of previously frozen fecal bacteria. Gut Microbes. 2013;4:125-35.

51. Hecker MT, Obrenovich ME, Cadnum JL, Jencson AL, Jain AK, Ho E, et al. Fecal microbiota transplantation by freeze-dried oral capsules for recurrent Clostridium difficile infection. Open Forum Infect Dis. 2016:3:ofw091.

52. Youngster I, Gerding DN. Editorial: making fecal microbiota transplantation easier to swallow: freeze-dried preparation for recurrent Clostridium difficile infections. Am J Gastroenterol. 2017;112:948-50.

53. Wrzosek L, Ciocan D, Borentain P, Spatz M, Puchois V, Hugot C, et al. Transplantation of human microbiota into conventional mice durably reshapes the gut microbiota [Internet]. Scientific Reports. 2018. https://doi. org/10.1038/s41598-018-25300-3.

54. Bermudez-Brito M, Plaza-Díaz J, Muñoz-Quezada S, Gómez-Llorente C, Gil A. Probiotic Mechanisms of Action [Internet]. Ann Nutr Metab. 2012:160-74. https://doi.org/10.1159/000342079.

55. Nastasi C, Candela M, Bonefeld CM, Geisler C, Hansen M, Krejsgaard T, et al. The effect of short-chain fatty acids on human monocyte-derived dendritic cells. Sci Rep. 2015;5:16148.

56. Arpaia N, Campbell C, Fan X, Dikiy S, van der Veeken J, deRoos P, et al. Metabolites produced by commensal bacteria promote peripheral regulatory T-cell generation. Nature. 2013;504:451-5. 
57. Zmora N, Zilberman-Schapira G, Suez J, Mor U, Dori-Bachash M, Bashiardes $\mathrm{S}$, et al. Personalized gut mucosal colonization resistance to empiric probiotics is associated with unique host and microbiome features [Internet]. Cell. 2018:1388-405.e21. https://doi.org/10.1016/j.cell.2018.08.041.

58. Varian BJ, Gourishetti S, Poutahidis T, Lakritz JR, Levkovich T, Kwok C, et al. Beneficial bacteria inhibit cachexia. Oncotarget. 2016;7:11803-16.

59. Alqayim MAJ. Effects of Lactobacillus acidophilus on pituitary-thyroid axis in growing rat [Internet]. Advances in Animal and. Vet Sci. 2015:269-75. https://doi.org/10.14737/journal.aavs/2015/3.5.269.275.

60. Zhou L, Li X, Ahmed A, Wu D, Liu L, Qiu J, et al. Gut microbe analysis between hyperthyroid and healthy individuals [Internet]. Curr Microbiol. 2014:675-80. https://doi.org/10.1007/s00284-014-0640-6.

61. Calcinaro F, Dionisi S, Marinaro M, Candeloro P, Bonato V, Marzotti S, et al. Oral probiotic administration induces interleukin-10 production and prevents spontaneous autoimmune diabetes in the non-obese diabetic mouse [Internet]. Diabetologia. 2005:1565-75. https://doi.org/10.1007/ s00125-005-1831-2.

62. Lavasani S, Dzhambazov B, Nouri M, Fåk F, Buske S, Molin G, et al. A novel probiotic mixture exerts a therapeutic effect on experimental autoimmune encephalomyelitis mediated by IL-10 producing regulatory T cells. PLoS One. 2010;5:e9009.

63. Rathi MS, Miles JN, Jennings PE. Weight gain during the treatment of thyrotoxicosis using conventional thyrostatic treatment. J Endocrinol Invest. 2008;31:505-8.

64. Rakov H, Engels K, Hönes GS, Strucksberg K-H, Moeller LC, Köhrle J, et al. Sex-specific phenotypes of hyperthyroidism and hypothyroidism in mice. Biol Sex Differ. 2016;7:36.

65. Eckstein AK, Losch C, Glowacka D, Schott M, Mann K, Esser J, et al. Euthyroid and primarily hypothyroid patients develop milder and significantly more asymmetrical Graves ophthalmopathy [Internet]. Br J Ophthalmol. 2009: 1052-6. https://doi.org/10.1136/bjo.2007.137265.

66. Wilkins $L$, Monga M, Miller AW. Defining dysbiosis for a cluster of chronic diseases. Sci Rep. 2019;9:12918.

67. Ivanov II, de Llanos Frutos R, Manel N, Yoshinaga K, Rifkin DB, Balfour Sartor $R$, et al. Specific microbiota direct the differentiation of IL-17-producing Thelper cells in the mucosa of the small intestine [Internet]. Cell Host \& Microbe. 2008:337-49. https://doi.org/10.1016/j.chom.2008.09.009.

68. Su X, Yin X, Liu Y, Yan X, Zhang S, Wang X, et al. Gut dysbiosis contributes to the imbalance of Treg and Th17 cells in Graves' disease patients by propionic acid. J Clin Endocrinol Metab. 2020;105. https://doi.org/10.1210/ clinem/dgaa511.

69. Fang S, Huang Y, Zhong S, Li Y, Zhang Y, Li Y, et al. Regulation of orbital fibrosis and adipogenesis by pathogenic Th17 cells in Graves orbitopathy [Internet]. J Clin Endocrinol Metab. 2017:4273-83. https://doi.org/10.1210/jc. 2017-01349

70. Fang S, Huang Y, Zhong S, Zhang Y, Liu X, Wang Y, et al. IL-17A Promotes RANTES expression, but Not IL-16, in orbital fibroblasts via CD40-CD40L combination in thyroid-associated ophthalmopathy [Internet]. Investigative Opthalmology \& Visual. Science. 2016:6123. https://doi.org/10.1167/iovs.1620199.

71. Al-Humaidi MA. Serum cytokines levels in Graves' disease. Saudi Med J. 2000;21:639-44.

72. Monroe JG, Haldar S, Prystowsky MB, Lammie P. Lymphokine regulation of inflammatory processes: interleukin-4 stimulates fibroblast proliferation. Clin Immunol Immunopathol. 1988;49:292-8.

73. He B, Hoang TK, Wang T, Ferris M, Taylor CM, Tian X, et al. Resetting microbiota by Lactobacillus reuteri inhibits $T$ reg deficiency-induced autoimmunity via adenosine A2A receptors. J Exp Med. 2017;214:107-23.

74. Oh JZ, Ravindran R, Chassaing B, Carvalho FA, Maddur MS, Bower M, et al. TLR5-mediated sensing of gut microbiota is necessary for antibody responses to seasonal influenza vaccination [Internet]. Immunity. 2014:47892. https://doi.org/10.1016/j.immuni.2014.08.009.

\section{Publisher's Note}

Springer Nature remains neutral with regard to jurisdictional claims in published maps and institutional affiliations.

\section{Ready to submit your research? Choose BMC and benefit from:}

- fast, convenient online submission

- thorough peer review by experienced researchers in your field

- rapid publication on acceptance

- support for research data, including large and complex data types

- gold Open Access which fosters wider collaboration and increased citations

- maximum visibility for your research: over $100 \mathrm{M}$ website views per year

At BMC, research is always in progress.

Learn more biomedcentral.com/submissions 